\title{
Dynamic discounting program of supply chain finance based on a financial information matching platform
}

\author{
Song Hua ${ }^{1} \cdot$ Yang Xiaoye $^{1}$ D $\cdot$ Song Yuanfang ${ }^{1}$
}

Accepted: 18 January 2022

(c) The Author(s), under exclusive licence to Springer Science+Business Media, LLC, part of Springer Nature 2022

\begin{abstract}
The dynamic discounting (DD) program based on the financial information matching platform (FIMP) is an emerging but underexplored supply chain finance (SCF) model. This study explores the configuration and operation of the DD program, compares and analyzes the DD decision between the traditional model and the FIMP-based DD model, and reveals how the latter model improves the cash flow of participants. Compared with the traditional model, the FIMP-based DD model can improve the accuracy of the daily discount rate for small and medium-sized enterprises; it offers enterprises more capital sources and helps participants determine an optimal payment period. There are three major contributions of this study. First, it explores the mechanism of the platform in promoting the DD model. The DD program is not participated in by a single buyer and supplier, but by one buyer with multiple $(N)$ suppliers based on an FIMP. Once the fundamental decision parameters can be met, several suppliers can enjoy early payment from a specific buyer, thereby improving liquidity of the benefitting participants. Second, the study offers important managerial insights. Suppliers can calculate the discount rate to motivate buyers' early payment choices. Besides, early payments could be constituted from a mixed portfolio with buyer's own capital and that from financial institutions. Third, the study explores key parameters. The discount rate is not only related to the cost of working capital but also to the financing costs. Based on the varying relationships between discount rate and capital costs, the present study makes a reasonable argument for the use of mixed funds and then calculates the optimal early payment period. Finally, this study conducts a sensitivity analysis with numerical examples, which finds that, by adopting the FIMP-based DD program, both buyers and suppliers enjoy a fairer procurement environment and more profitable multi-lateral relationships.
\end{abstract}

Keywords Dynamic discounting · Financial information matching platform · Small and medium-sized enterprises $\cdot$ Supply chain finance $\cdot$ Working capital

Yang Xiaoye

yangxiaoye_leaf@126.com

1 Business School, Chinese Supply Chain Strategic Management Center, Renmin University of China, 100872 Beijing, China 


\section{Introduction}

\subsection{Background and motivation}

For small and medium-sized enterprises (SMEs), financing has become a critical obstacle to industrial development owing to its high cost and low return. As competition and information asymmetry becomes more fierce, SMEs in the supply chain are suffering increasing working capital pressure (Berger and Udell 2006). The extended payment terms of suppliers are recognized as a financial problem worldwide since the 2008 global economic downturn (Oliveira and Handfield 2017). In 2009, for example, 43\% of the SMEs in Belgium and 50\% of those in Netherlands experienced payment delays on their receivables (OECD 2009). The average payment delay in the Government-to-business model in Europe is nearly half of the agreed contractual terms according to Connell's (Connell 2014) report, who collected payment duration data across 26 European countries in 2013. Additionally, according to the Hackett Group, a US consulting firm, the average payment delay of 1,000 US listed companies increased from 40.1 days in 2008 to 56.7 days in 2017 (Group 2018). This situation has worsened due to the impact of COVID-19. For instance, based on KPMG's recent report "COVID-19 Global Tax Developments Summary," payments were delayed severely on commercial receivables and global firms' liquidity needs increased from 5 days to 74 days in 2020 due to the COVID-19 outbreak worldwide (Hermes 2021). According to Coface's (Coface 2020) recent research on the payment status of SMEs in China, the proportion of average credit terms exceeding 120 days has almost doubled in two years-from $12 \%$ in 2017 to $23 \%$ in 2020. In practice, $50 \%$ of the respondents offered maximum payment terms exceeding 120 days. The proportion of companies experiencing payment delays that exceeded 120 days reached $37 \%$ in $2019,6 \%$ more than in 2018 . More ominously, more than a quarter of companies $(27 \%$ ) experienced ultra-long payment delays (over 180 days), in which the payment value exceeded $10 \%$ of their annual turnover. When these delayed payments constitute a large proportion of total annual turnover, a company's cash flow may be at risk (Coface 2020). In addition, shortage of working capital among certain SMEs will further negatively affect its upstream and downstream business partners (Gharaei et al. 2020; Rabbani et al. 2020), causing widespread funding problems. To solve this problem, it is, therefore, necessary to accelerate cash flow along the pipeline and promote financing for SMEs through innovative approaches. Accordingly, the inter-organizational management of financial flows, based on the interaction between operations and financing, SCF has become a mainstream method in this field, whereby companies collaborate with financial institutions to provide additional liquidity to strategic suppliers (Wuttke et al. 2013; Caniato et al. 2019).

The essence of SCF is to optimize the operation of the supply chain, improve the capital efficiency of each member in the supply chain, and ultimately enhance the competitiveness of the whole supply chain through financial services and activities. In a narrow sense, SCF refers to short-term financing activities for SMEs at certain stages of the supply chain, mainly including accounts receivable and payable financing (e.g., factoring, reverse factoring, forfeiting), inventory financing (e.g., warehouse receipt pledge, inventory pledge), and advance payment financing (e.g., confirming storage) (Bi et al. 2018; Bougheas et al. 2009; Hofmann 2009; Zhao and Huchzermeier 2019). In a broad sense, SCF not only enables financing but also promotes cash flow among all stakeholders, facilitating the best operational performance by optimizing and improving the capital efficiency of the whole supply chain (Bals 2019; Hua et al. 2018). Traditional SCF is provided by banks, factoring companies, and other financial institutions in terms of large core enterprise credits, and the financing loans are provided to 
their suppliers. However, reverse factoring is heavily dependent on core companies that are usually reluctant to cooperate with financial institutes, and most SMEs cannot be covered by supply chain financial loans. Therefore, it is necessary to solve the funds shortage problem of SMEs in the supply chain by finding better ways of optimizing working capital. One of the most important ways is through a dynamic discounting (DD) program.

Although dynamic discount technology has existed since 2010, it has recently become a mainstream supply chain financial method in United States and European countries; so far in Asia, it is still in its infancy. DD program refers to a dynamic settlement that properly utilizes the visibility of the trade process provided by the platform and enables suppliers and buyers to reach an agreement on a fixed daily discount on the nominal invoice value, finally realizing a "customized" application of early payment discounts. As a flexible and convenient solution to reduce accounts receivable, DD provides a stable mechanism to offset financial negative externalities (Gelsomino et al. 2016). Specifically, the dynamic settlement of invoices under DD benefits buyer-supplier dyadic relationships. For example, Columbia Sportswear Company has reached an early payment discount plan with its suppliers. It chooses to pay at a specific discount rate and time whereby suppliers can improve their turnover rate of accounts receivable and the company can pay for its purchases at lower prices (Inc 2005).

Recently, the transaction volume brought about by electronic invoice adoption and digital and intelligent settlement services is increasing. If a DD program is to be initiated by individual enterprises and there is a constant search for upstream and downstream enterprises willing to accept this program, it will be limited in its ability to solve the working capital shortage of SMEs due to the high transaction costs. Therefore, a DD program must evolve from the traditional peer-to-peer mode to a real-time and intelligent platform-based mode. Against this background, a new model of SCF has emerged, namely, SCF based on a FIMP. This model enables SMEs upstream and downstream in the supply chain to independently grant their core customers an incremental discount on the nominal invoice value to encourage them to pay in advance. SMEs can propose their demands according to their own capital situation, and both parties can negotiate an advance period and discount rate to better match the capital needs of SMEs (Demica 2007; Wandhöfer 2019). The first FIMP in the world, C2FO, has helped more than 300,000 enterprises in 173 countries and regions solve the problem of working capital financing. Presently, this platform has matched accounts receivable and accounts payable of more than 1.2 trillion US dollars in total, using the DD program as a key business element. In addition, as the foundation of DD's operation, FIMP enables the DD program to realize economies of scale and other operational advantages. First, with more business transactions integrated into the platform, the platform makes full use of digital and information technology to activate working capital and uses financial technology tools to quickly and economically serve core enterprises and their suppliers on both the payable and receivable to establish a new working capital flow system (Farrell and Greig 2016). Second, unlike traditional SCF, the information matching platform integrates the distinctive working capital requirements of different suppliers into the same platform, and builds a "working capital market," which helps to form networked exchanges and interactions, configures a large number of dispersed orders, and achieves DD in a unified way. In addition, the agglomeration of information by the multi-level suppliers and core enterprises creates a fair financing market environment and reduces financing cost discrimination. Therefore, the platform not only delivers benefits for the core enterprises but also alleviates liquidity problems for SMEs. 


\subsection{Research questions and major contributions}

DD is a "demand-based" solution (Gelsomino et al. 2016, 2018) that allows a supplier choose when to accept the buyer's early payment application in coping with seasonal fund variations. However, with the increase of DD users, the program needs to be supported by FIMP in improving matching efficiency. Thus, studying optimal decision-making in this situation is necessary. Therefore, this study specifically aims to address the following research questions:

(1) What are the main differences between a traditional DD model and the DD model based on FIMP?

(2) What is the reasonable discount rate to be offered by SME suppliers? Is there an optimal value to maximize the possibility of DD settlement between the participants based on FIMP?

(3) In a DD program based on FIMP, if the buyers have insufficient working capital, how can they optimize the capital utilization scheme from multiple sources to maximize profits?

(4) In DD program based on FIMP, how can the optimal payment period decision be determined by the two participants?

To address the above research questions, this study first analyzes the traditional DD model and the FIMP-based DD model, and formulates the best decision scheme based on FIMP. The main decision parameters include the daily dynamic discount rate, working capital amount, payment period and so on. Second, this study makes a numerical analysis examining whether the propositions derived from the model can apply to practical settings, given the different values of the parameters acquired from the investigation. This study contributes to the literature on SCF and DD programs by providing a better understanding of the relevant benefits and parameters of the model. Therefore, the main contributions of this research are as follows:

(1) The DD model based on the FIMP in this study explores the mechanism of the platform in promoting the DD model. The platform can match DD applications of multiple $(N)$ suppliers for a single buyer at a time, and provide an environment for them to automatically trigger an optimal payment period. Moreover, the FIMP that links SME suppliers with core enterprises, creates a fairly financed capital market, eliminates cost discrimination, helps SMEs gain more autonomy, and provides a new perspective to solve capital shortage.

(2) This study offers important management insights for supply chain enterprises to improve their profits and optimize capital flow. Suppliers can set the discount rate range to ensure that buyers are stimulated to early pay, and calculate the optimal discount rate to improve the profits for participants. Furthermore, the buyer can optimize the portfolio proportion of mixed source funds according to the capital cost, discount rate, and working capital amount, and further play the role of core enterprises in improving the capital liquidity of the whole supply chain.

(3) This study discusses the key parameters-discount rate, working capital constraints, and optimal payment period, and finds the differences from previous studies. This study proposes that based on FIMP, determining the discount rate needs to consider not only the cost of working capital but also the cost of bank financing. Additionally, this study considers that the buyer may also have capital constraints, and according to the key parameters, could make a reasonable argument for the use of mixed funding. Moreover, the optimal early payment period of DD settlement based on FIMP is also an important finding of this study, since previous studies have not found an accurate measure. 
The rest of the paper is organized as follows: Sect. 2 highlights the relevant theoretical background through a literature review; Sect. 3 presents the model parameters and basic assumptions; Sect. 4 analyzes the DD model; Sect. 5 compares the differences between the traditional DD decision situation and the DD decision situation based on FIMP; Sect. 6 presents the numerical example and parameter sensitivity test. Finally, Sect. 7 summarizes the research and advances prospects for future research.

\section{Literature review}

\subsection{Supply chain finance and dynamic discounting program}

To optimize the cash flow of enterprises, research on SCF is emerging and developing rapidly (Caniato et al. 2019; Chen et al. 2020). Research on SCF describes the interactions among capital, operations, and risk management, and includes the integration mechanisms of logistics, cash flow, and information flow (Babich and Kouvelis 2018). There are several schemes of SCF, such as early payment, delayed payment, debt financing, equity financing, financial insurance, partial guarantee factoring, and reverse factoring (Gelsomino et al. 2016b). In general, the previous literature on SCF adopts one of two perspectives-financial orientation and supply chain orientation (Gelsomino et al. 2016b; Hua et al. 2018; Pellegrino et al. 2019). Financial-oriented SCF usually regards SCF as a type of short-term financial plan (Lamoureux and Evans 2011; More and Basu 2013; Lekkakos and Serrano 2016; Wu et al. 2019) that focuses on optimizing accounts payable and accounts receivable in the supply chain. Supply chain-oriented SCF, meanwhile, regards SCF as a way to optimize working capital and improve the financial performance more generally. It focuses on the cooperation among supply chain participants rather than on financial products (Pfohl and Gomm 2009; Randall and Farris 2009; Ma et al. 2020; Sokolinskiy et al. 2018). However, any single SCF scheme has limitations in terms of participants' diversity and relational complexity in business supply chains. In a broader sense, the role of SCF is to improve the operational efficiency as well as the efficiency of working capital of the supply chain. In this sense, the DD program is especially and gradually favored by more SMEs.

The DD program relies on buyers making early payments in return for a discount offered by the supplier on the goods or services purchased. Early payment can be settled by the buyer's own excess cash or by an intermediary financing provider (Templar et al. 2016). Previous studies have shown that DD is derived from the typical cash discount policy in trade credit practice, allowing the dynamic settlement of invoices through some integrated buyersupplier platforms (Kopalle et al. 1999; den Boer 2015; Gelsomino et al. 2018). DD stems from the fundamental recognition that the large-scale application of a static discount weakens the potential profits from differentiated pre-payment demands (Randall and Farris 2009). A flexible cash discount policy-in which the buyer and supplier can settle the invoice at any time within the standard payment terms in exchange for a certain percentage of discountcan provide more benefits to the related companies (den Boer 2015). DD can be initiated by two participants: buyers (i.e., the buyer declares the acceptable discount rate, and the supplier responds by accepting early payment) or suppliers (i.e., the supplier proposes a proper discount, and the buyer accepts the proposal). Meanwhile, DD can also increase the trust and cooperation level among participants (Templar et al. 2016). In addition, DD helps to reduce the capital cost of both supply and demand and accelerates the speed of capital turnover in the whole supply chain. On the one hand, Gelsomino et al. (2016) show that DD 
can reduce the uncertainty of the supplier's working capital demand and help to plan the cash flow better. On the other hand, it can help the buyer determine the optimal payment period and reduce the financial cost. Furthermore, DD can accelerate the operation and effectively improve the stability and reliability of the supply chain; thus DD plays an important role in relieving the capital pressure of SMEs (Hofmann and Kotzab 2010; Wandfluh et al. 2016).

Previous research has studied DD from the perspective of improving supply chain operation efficiency. Several sources show that the inventory (Gharaei et al. 2019; Kazemi et al. 2018), order quantity (Giri and Masanta 2020; Shekarabi et al. 2019), product price and quality (Duan et al. 2018; Shah et al. 2020) in the process of production and operation will have an impact on the overall and individual profits of the supply chain. The research of DD in the production and operation area mainly includes the discount and payment methods, discount, inventory, transportation management, and discount and product quality (Jaggi et al. 2017; Jana and Das 2017; Shi et al. 2021). However, in the actual business activities, collaboration, price strategy, and product quality cannot be altered rapidly by SMEs. Therefore, this study considers ways to improve the profit of SMEs from the perspective of improving the liquidity of supply chain capital without changing the factors such as order quantity, inventory, and price, and provide a feasible way for SMEs to improve their own profits and supply chain efficiency.

Therefore, based on the above literature review of DD, it can be seen that the previous research on DD focused more on the peer-to-peer supply-demand relationship in the supply chain. As the number of participants and transaction settlements increase, the decision scheme of DD changes, while the differences have not been studied adequately. Moreover, previous research explored the impact of quantity DD mainly on the production cost aspects. However, there is a gap regarding DD as a supply chain financial model to alleviate the capital shortage and DD to improve the efficient utilization of funds.

\subsection{Supply chain finance and financial information matching platform}

The development of SCF requires specialized information, communication, technical abilities, and multi-agent connection capabilities. Specialization and platformization are the inevitable tendencies of SCF development (Xiangjun and Lingyun 2012; Bals 2019; Chen et al. 2019; Song et al. 2019). FIMP is one of the most advanced models of novel SCF solutions (Zhou et al. 2018; Jia et al. 2020). FIMP is a service-oriented infrastructure, which provides necessary applications and information to all participants to promote smooth transactions and financing activities. Spagnoletti et al. (2015) propose that any information or digital platform contains three architectural elements: a core component, complements, and an interface. A platform-based system is a special type of a modular system; it is composed by a set of relatively stable core services of low variety, a set of evolving peripheral complements of high variety, and a set of interfaces that link the core components to their complements (Baldwin and Woodard 2009). In an FIMP, the core component includes financial information disclosure (e.g., the volume of receivables and payables, payment days), financial requirements and conditions matching (e.g., the communication and negotiation between suppliers and customers), and payment/financing activities (e.g., early payment or financing from financial institutes). From the complement perspective, an FIMP grows in complexity as it accommodates heterogeneous suppliers' needs (early payment or capital requirement) while maintaining backward compatibility (customers' situation and commitment) and horizontal compatibility (payment or financing conditions) across different components. Therefore, an FIMP enriches the diversity of SCF, resulting in increased financial services complexity. 
In addition, combined with a transactional information and financial resources interface, an FIMP not only meets the customized capital requirements of SME suppliers, but also realizes other potential benefits, reflected in both the suppliers' and customers' economic payoff and operational competitiveness.

Therefore, information sharing, collaboration, and collective actions can be realized through an FIMP (Tiwana et al. 2010). By analyzing and forecasting the cash flow along the pipeline, the platform enables cash flow monitoring, liquidity shortages analysis, financing channels search and establishment, and also helps enterprises find appropriate approaches to optimize their working capital (Boyson et al. 2003; Zhou et al. 2018). More specifically, the FIMP can collate and summarize the payment terms of certain trading partners (Zhou et al. 2018), guide and reward existing partnerships by equally cultivating and encouraging better cash-to-cash cycle management, thereby realizing inherent advantages for each company along the pipeline (Randall and Farris 2009). Powered by innovative technologies such as blockchain and the Internet of Things, FIMP can provide an aggregation service to clients, with financing availability from multiple banks and non-banking institutions. The multi-bank nature increases competition among banks for the provision of financing. This not only puts pressure on margins but also drives improvements in the quality of financial services, with streamlined onboarding and superior interfaces that make them easier to use (Lahkani et al. 2020). Further, due to the network externality, with the increased of number and types of enterprises joining the network, the guidance that the FIMP can provide for SMEs is richer and more accurate, and the solution can provide customized financing services for SMEs (Cheng 2020; Dou et al. 2018). Moreover, unbalanced profits will inevitably affect the enthusiasm of supply chain participants, and FIMP addresses this by balancing the profits between the supply and demand sides; it adjusts the profit distribution scheme and tries to prevent any party from losing profits (Narasimhan et al. 2018; Schor and Attwood-Charles 2017). Currently, several FIMPs (such as C2FO, Taulia, SAP Ariba, and PrimeRevenue) use $\mathrm{DD}$ as the main approach to implement SCF. The reason is that DD can increase buyers' benefits and reduce the uncertainty of suppliers' cash flow. Therefore, DD is an important SCF mode that is supported by the FIMP.

Nevertheless, the mechanism and decision-making changes of DD based on FIMP have not been explored previously. Previous studies mainly discuss the application scenarios of DD and the impact of buyers' early payments on improving the working capital operational efficiency of the supply chain, as well as the impact on different supply chain financial schemes (including dynamic discount) in reducing capital shortage (Gelsomino et al. 2019). However, few studies have focused on the specific buyer-supplier relationship or the DD program based on a FIMP realizing information matching and large-scale order processing. Previous studies also did not identify how to determine the key parameters of working capital costs and requirements, as well as the key parameters of DD schemes that affect adoption and benefits. Therefore, this study aims to bridge the gaps in literature and overcome limitations identified above. By constructing a DD decision-making model, this study addresses the discount rate, optimal payment methods when capital is constrained, optimal payment period, and other parameters. This study investigates whether these considerations and insights hold in the case of the concurrent occurrence of multiple variables, followed by a sensitivity analysis on the optimal combination of parameters in different situations. 


\section{Dynamic discounting program description}

\subsection{Main process of dynamic discounting}

DD has four main process stages (Thangam 2012). The first is invoice uploading, which starts when the invoices are composed and exchanged electronically between the buyer and the supplier (for instance, through a cloud-based FIMP), and ends when the electronic invoice is sent to the buyer. The second is invoice receiving. It includes all the activities carried out by the buyer after receiving the invoice (i.e., after uploading of the invoice on the FIMP), and ends with the approval of the payment invoice. The third is negotiation and agreement: it starts with the submission of an early payment proposal (EPP) and ends with the definition of the updated payment terms. During this stage, the supplier and buyer communicate and negotiate to reach an agreement. The supplier and the buyer determine the revised payment terms, such as payment discount and payment period. If the terms of payment are not agreed or the buyer refuses to accept, the supplier may compromise to allow the two to reach an agreement on the payment period, price, and other elements. The supplier then revises the corresponding documents (Matus et al. 2017). The last step is invoice archiving. Notably, the buyers can accept or reject the suppliers' request for a specific discount. When the request is finally accepted, or when the standard payment terms have been met, the due date and discount will be updated on the buyer's enterprise resource planning system to complete the payment in advance. Invoice archiving is completed by one of three events: the agreement on an EPP (and the consequent update of the invoice terms), the fulfillment of contractual payment terms, or mandatory archiving dictated by specific regulations (e.g., 15 days after invoice receipt). This process repeats until the proposal is accepted or the payment date arrives.

\subsection{Inputs}

Gelsomino et al. (2016a) proposed a DD model based on the assumption that the buyer's commercial credit is higher than the supplier's commercial credit. Specifically, $r_{s}$ is the cost to the supplier of financing one unit of cash for one day (e.g., the daily cost of a form of short-term debt comparable to trade credit, such as invoice discounting). The buyer can access short-term debt (similarly to the suppliers) at a cost of $r_{b}$ per unit of cash per day, or can use its own liquidity (e.g., generated from operating activities), at a cost of $y_{0}$ per unit of cash per day. Given the above-mentioned assumption, it follows that $y_{0}<r_{s}, r_{b}<r_{s}$. If the buyer needs to use working capital (an amount equal to $l i q$ ) to pay an invoice in advance, there is an attached opportunity cost: that working capital cannot be used for other purposes (Chen and $\mathrm{Rq} 2021$ ). Each issued invoice has standard payment terms of $G$ days. Invoices issued at $t=0$ are paid at $t=G$, with $t=\{0,1, \cdots, G\}$, while the early settlement period is equal to ep $(t)$. By assuming that all the suppliers are similar, therefore, all the invoices within an invoice cycle have the same nominal value, $v_{n}$ that is, the amount the buyer must pay the supplier under standard invoice conditions. Daily discount $(d d)$, multiplied by the number of days in advance, constitutes the actual discount received by the buyer. The financial cost to the buyer is $f_{c}(t)$, and may either be the cost of working capital or the cost of short-term debt due. The financial savings of the supplier is $f_{s}(t)$, and $d(t)$ is the buyer's discount. 


\subsection{Assumptions}

To simplify the model and facilitate comparison, the following assumptions are made in this study: (1) in an invoice cycle, there are $N$ undifferentiated suppliers and 1 buyer; (2) regardless of the buyer's inability to obtain debt; (3) at the end of the invoice cycle, the buyer can pay off the total debt owed to financial institutions; (4) the invoice is paid on the same day that the EPP is accepted; (5) due to the short invoice period, it is assumed that the fund cost and return change linearly with time; (6) the buyer's payment period will not exceed the standard invoice period.

\section{Basic model of dynamic discounting}

As the previous review shows, this study does not discuss dynamic discount by changing order quantity, inventory quantity, and product price (Dubey et al. 2015; Gharaei et al. 2021), but analyzes it from the perspective of SCF. If DD is implemented, the payment will be completed dynamically before $\mathrm{G}$ days, and the actual discount is not only the buyer's income but also the suppliers' loss. In addition, due to the pre-payment, the buyer incurs financial costs, while the supplier gains financial savings. Therefore, the buyer's expected profit $\pi_{b}=$ discounts financial cost, and the suppliers' expected profits $\pi_{s}=$ financial saving discounts.

When the buyer and supplier reach an EPP agreement on the platform, the early period is equal to ep $(t)$, which is the number of days that the invoice must be settled in advance. In this study, the payment days are considered to be integers, so ep $(t)=G-t, \operatorname{ep}(t) \in[0, G]$. Where the EPP is accepted on day $t$, the discounted value that the buyer will pay to the supplier is as follows.

$$
d v(t)=v_{n} \cdot[1-d d \cdot e p(t)]
$$

The discount offered by the supplier (or the discount received by the buyer) is

$$
d(t)=v_{n} \cdot d d \cdot e p(t)
$$

The financial saving for the supplier is

$$
f_{s}(t)=v_{n} \cdot[1-d d \cdot e p(t)] \cdot r_{s} \cdot e p(t)
$$

According to the previous analysis, based on FIMP DD model, the buyer's financial cost depends on the source of funds used for early payments. It may be the opportunity cost of occupying working capital or the cost of short-term debt from financial institutions. As stated above, the buyer "allocates" an amount of liquidity $(l i q)$ to the program. If the working capital in the DD program cannot be used for other investments, an opportunity cost is incurred. In this study, the yield of an alternative investment is used as a proxy for the opportunity cost. Although this assumption might seem restrictive, its effect on the outcome of the model is considered trivial (Lee and Rhee 2011). Generally, working capital is deposited in a bank or invested in a short-term operation before payment, and the buyer "allocates" an amount of liquidity $(l i q)$ to the program. Under the standard payment terms, the buyer's short-term income from working capital is $l i q \cdot G \cdot y_{0}$, and the opportunity cost is $d v(t) \cdot e p(t) \cdot y_{0}$. Therefore, the buyer's profit is liq $\cdot G \cdot y_{0}-d v(t) \cdot \operatorname{ep}(t) \cdot y_{0}$. If short-term debt is selected for payment, the buyer would also receive the working capital income as $l i q \cdot G \cdot y_{0}$. The financing cost of financial institutions is $d v(t) \cdot e p(t) \cdot r_{b}$ and therefore, in this situation, the buyer's profit is $l i q \cdot G \cdot y_{0}-d v(t) \cdot e p(t) \cdot r_{b}$. Overall, the financial cost for a given buyer 
is shown in Eq. (4).

$$
f_{c}(t)= \begin{cases}d v(t) \cdot e p(t) \cdot y_{0} & \text { working capital cost } \\ d v(t) \cdot e p(t) \cdot r_{b} & \text { short-term debt cost }\end{cases}
$$

When the payment time is $t$, the change in profit relative to the payment without a DD program is given in Eqs. (5) and (6), respectively.

$$
\begin{aligned}
\pi_{b} & =\left[d(t)+l i q \cdot G \cdot y_{0}-f_{c}(t)\right]-l i q \cdot G \cdot y_{0} \\
\pi_{s} & =f_{s}(t)-d(t)
\end{aligned}
$$

By substituting Eqs. (2) and (4) into (5), the difference in the buyer's profit from using the working capital payment method compared to liquidity provided by a financial institute is given in Eqs. (7) and (8), respectively.

$$
\begin{aligned}
& \pi_{b_{-} w}=v_{n} \cdot d d \cdot y_{0} \cdot e p(t)^{2}+v_{n} \cdot\left(d d-y_{0}\right) \cdot e p(t) \\
& \text { s.t. } \quad 0 \leq e p(t) \leq G \\
& \pi_{b_{-} d}=v_{n} \cdot d d \cdot r_{b} \cdot e p(t)^{2}+v_{n} \cdot\left(d d-r_{b}\right) \cdot e p(t) \\
& \text { s.t. } \quad 0 \leq e p(t) \leq G
\end{aligned}
$$

By substituting Eqs. (2) and (3) into (6), the supplier's profit can be obtained as follows:

$$
\begin{aligned}
& \pi_{s}=-v_{n} \cdot d d \cdot r_{s} \cdot e p(t)^{2}+v_{n} \cdot\left(r_{s}-d d\right) \cdot e p(t) \\
& \text { s.t. } 0 \leq e p(t) \leq G
\end{aligned}
$$

Therefore, when there are $N$ undifferentiated suppliers and one buyer, and the probability that the buyer and the supplier reach a payment agreement at time $t$ is set as $\theta$, according to Eqs. (7), (8), and (9), in an invoice cycle $v_{n}$, the expected profit of the buyer's payment with the working capital method or with other financial institutes; the expected profit of the supplier are expressed as Eqs. (10), (11), and (12).

$$
\begin{aligned}
& \Pi_{b_{-} w}=\sum_{t=0}^{G} \theta \cdot N \cdot v_{n} \cdot d d \cdot e p(t)-\sum_{t=0}^{G} \theta \cdot N \cdot v_{n} \cdot[1-d d \cdot e p(t)] \cdot e p(t) \cdot y_{0} \\
& \Pi_{b_{-} d}=\sum_{t=0}^{G} \theta \cdot N \cdot v_{n} \cdot d d \cdot e p(t)-\sum_{t=0}^{G} \theta \cdot N \cdot v_{n} \cdot[1-d d \cdot e p(t)] \cdot e p(t) \cdot r_{b} \\
& \Pi_{s}=\sum_{t=0}^{G} \theta \cdot N \cdot v_{n} \cdot r_{s} \cdot[1-d d \cdot \operatorname{ep}(t)] \cdot \operatorname{ep}(t)-\sum_{t=0}^{G} \theta \cdot N \cdot v_{n} \cdot d d \cdot e p(t)
\end{aligned}
$$

\section{Dynamic discounting decision analysis}

The DD model can be divided into FIMP-supported and non-FIMP-supported (this study refers to the non-FIMP-supported DD program as the traditional DD program). In the traditional DD program, the core enterprise interacts with several SME suppliers. Due to the large number of scattered orders, the buyer needs to manage each payment order separately and communicate the discount details individually. Concurrently, as the number of suppliers is increasing, the buyer needs to invest more resources in multiple DD orders. Therefore, the suppliers cannot accurately judge whether the buyer is willing to accept the DD settlement. Furthermore, as the suppliers do not know the buyer's capital cost, the number of suppliers, the source of funds, and other information, they can only infer the discount rate based on 
their own information; thus, it is unclear to them whether the buyers can accept these terms. However, in the scenario of FIMP, the information flow between the suppliers and the buyer is transparent, and the platform provides more decision-making references for DD participants to ensure that the profits of both parties can be improved simultaneously. Moreover, FIMP provides more capital sources for the buyer, urges them to use a capital combination more reasonably in the DD program, and provides benchmark parameters for the suppliers as a reference, which helps to determine the optimal discount rate and discount range and reasonably optimize the pre-payment period. Therefore, the main differences between the traditional DD model and the DD model based on FIMP are reflected in the discount rate, working capital constraints, and the optimal early payment period. The following section differentiates between the decision-making of traditional DD and of FIMP-based DD, by highlighting the aforementioned aspects.

\subsection{Traditional dynamic discount program decision}

In the traditional DD program, several SME suppliers use DD to encourage their buyer to pay in advance. However, as the buyer is the core enterprise, it is often unrealistic for them to carry out multiple rounds of a repeated bargaining process on the important parameters of DD (including discount rate, payment period, and other factors) (Giri and Bardhan 2014; Sarkar and Giri 2020; Yin et al. 2016). Thus, the suppliers can only infer the range of the discount rate according to their own capital cost, and then provide a discount rate and payment period based on the buyer's situation. Additionally, due to the increasing number of suppliers, the buyer may not be able to provide sufficient working capital at any given time to meet the DD demand of all suppliers; thus, the buyer could have insufficient working capital. Therefore, based on the above characteristics of the traditional DD program, this study analyzes this decision-making process.

(1) Discount rate $d d_{1}$ For the supplier, the discount rate provided should ensure that profit is not less than zero at any time during the invoice cycle. If the supplier's profit is zero, it implies that, although the supplier has not obtained any profit but has recovered the accounts receivable in advance, the supplier is also willing to agree to the settlement. The buyer's profit must also be greater than zero; that is, buying should be profitable, resulting in an incentive for both parties to reach an early payment agreement. Hence, first, for the supplier, since $\pi_{s}$ is a convex function passing through the origin, it only needs to satisfy the condition that $\pi_{s}$ is not less than zero at the two endpoints of $e p(t)$; the concluding equation can be drawn as:

$$
0<d d_{1} \leq r_{s} /\left(r_{s} \cdot G+1\right)
$$

Second, the suppliers cannot get the buyer's capital cost information, and thus, the suppliers cannot speculate the discount rate range that the buyer can accept. The discount rate given by the suppliers may cause the buyer's profit to be greater than or less than zero. The buyer will be willing to pay early only when the discount rate leads to increased profits from the DD project. In this situation, the suppliers can only provide a rough range of discount rate, see Eq. (13).

(2) Working capital constraints li $_{1}$ and early payment period ep $(t)_{1}$ For the buyer, if the discount rate provided by the suppliers can generate profit greater than zero, then the buyer will be willing to attend the DD program. However, as the buyer may face financial constraints, there may be not enough funds to meet the DD application of all suppliers. 
Even if the buyer has other sources of funds, it is not economical and feasible to use these for individual and scattered short-term loans for all suppliers at any time. Therefore, the buyer can only use the existing working capital to meet the flexible dynamic discount items of multiple SME suppliers.

According to Assumption 6, at the end of the invoice cycle, the buyer needs to be able to pay all the suppliers. As the buyer's payment amount is $N \cdot v_{n} \cdot\left[1-d d_{1} \cdot e p(t)_{1}\right]$, only when $\operatorname{ep}(t)_{1}$ is maximum $G$, the buyer's working capital can be used at least, so if the buyer wants to be able to complete the payment on time, they need to prepare at least li $q_{C}=N \cdot v_{n} \cdot\left(1-d d_{1} \cdot G\right)$. Then, this study sets a critical value of $e p(t)_{L}$ if the buyer uses working capital to pay all suppliers; $e p(t)_{1}$ needs to at least exceed $e p(t)_{L}$, thus getting $e p(t)_{L}=\left(N \cdot v_{n}-l i q\right) /\left(N \cdot v_{n} \cdot d d\right)$. The buyer can only choose the payment method freely at this time, when $\operatorname{ep}(t)_{1}$ is in the range of $\left[\operatorname{ep}(t)_{L}, G\right]$. If $\operatorname{ep}(t)_{1}$ is in the range of $\left[0, \operatorname{ep}(t)_{L}-1\right]$, the buyer will refuse early payment to some suppliers, which is inconsistent with the assumption. Therefore, from the above analysis, it can be concluded that the working capital of the buyer should at least satisfy Eq. (14) and the early payment period should satisfy Eq. (15).

$$
\begin{aligned}
& l i q_{1} \geq l i q_{C} \\
& \frac{N \cdot v_{n}-l i q}{N \cdot v_{n} \cdot d d_{1} \leq e p(t)_{1} \leq G}
\end{aligned}
$$

According to the above analysis, due to the limitation of working capital or the inability to guarantee that the buyer will pay early at a fixed time, Eq. (15) can only determine the payment period range of the buyer. Therefore, when the probability of the suppliers and the buyer to reach payment at time $t$ is $\theta$, the profits of the suppliers and the buyer are shown in Eqs. (16) and (17).

$$
\begin{aligned}
& \underset{\substack{l i q_{C} \leq l i q<l i q_{\max } \\
\Pi_{b 1-w}}}{G}=\sum_{e p(t)_{1}=e p(t)_{L}}^{G} \theta \cdot N \cdot v_{n} \cdot d d_{1} \cdot e p(t) \\
& -\sum_{e p(t)_{1}=e p(t)_{L}}^{G} \theta \cdot N \cdot v_{n} \cdot y_{0} \cdot\left[1-d d_{1} \cdot e p(t)\right] \cdot e p(t) \\
& \prod_{l i q_{C} \leq l i q<l i q_{\max }}^{\Pi_{s 1}}=\sum_{e p(t)=e p(t)_{L}}^{G} \theta \cdot N \cdot v_{n} \cdot r_{s} \cdot\left[1-d d_{1} \cdot e p(t)\right] \cdot e p(t) \\
& -\sum_{e p(t)=e p(t)_{L}}^{G} \theta \cdot N \cdot v_{n} \cdot d d_{1} \cdot e p(t)
\end{aligned}
$$

According to the above analysis, there are some problems in the process of the DD program between multiple suppliers and a core enterprise buyer: (1) because the SME suppliers do not know the buyer's capital cost, the number of suppliers, and other factors, they are unable to accurately determine the reasonable range of discount rate to ensure the buyer's profit is greater than zero; (2) due to the uncertainty of a reasonable range of discount rate, suppliers also cannot determine the accurate optimal discount rate that can be accepted by the buyer. The above situations will greatly affect the buyer's payment enthusiasm and the buyer may directly refuse the suppliers' application for DD. (3) In the traditional scenario, the buyer's capital constraint is in the range of $l i q_{C}$ and $l i q_{\max }$, and if suppliers' demand for capital is beyond the range, DD cannot be smoothly implemented. (4) In the range of $\left[\operatorname{ep}(t)_{L}, G\right]$, 
the buyer can determine the timing of payment in their own interest without considering the suppliers' benefit, which can result in unbalanced benefits for both sides.

\subsection{Dynamic discounting program decision based on financial information matching platform}

In the DD program based on FIMP, the platform provides more ways to optimize decisions, and has an impact on the important decision-making factors of participants.

(1) Discount rate $d d$ In DD program based on FIMP, the platform can collect and share the buyer's and the suppliers' capital cost. The capital cost of the buyer includes not only the cost of its own capital, but also the capital cost from the bank's short-term financing. Moreover, because the buyer may consider DD transactions with many SME suppliers, they need to first provide the discount rate to facilitate the buyer's decision-making. Then, the buyer will have three choices: direct acceptance, direct rejection, or a suspension with a conditional modification of the discount rate. The latter two results will seriously reduce the buyer's willingness to adopt the DD, in that, the invoice cycle is limited, and repeated modification may affect the early payment period. However, when the buyer is faced with multiple SMEs, the volume of communications will increase transaction costs. Therefore, the discount rate provided by rational suppliers should equilibrate both their own and buyer's profits to a point where both are greater than zero, and the supplier can provide an exact discount rate that the buyer will accept more readily. Therefore, ways to determine a reasonable range of discount rate and an optimal discount rate should be investigated.

As FIMP shares capital cost between the suppliers and the buyer, the values of $r_{s}, r_{b}$ and $y_{0}$ can be obtained and used to infer each party's decision choices. The analysis of the traditional DD model concludes that, to ensure that suppliers' profits are greater than zero, the discount rate should satisfy $0<d d_{1} \leq r_{s} /\left(r_{s} \cdot G+1\right)$. Similarly, in the FIMP model, suppliers should first ensure that their profits are greater than zero, and the discount rate should also satisfy $0<d d_{2} \leq r_{s} /\left(r_{s} \cdot G+1\right)$. Furthermore, the buyer has the motivation to obtain profits through the DD model, according to Eqs. (7) and (8). Regardless of when the early payment is fulfilled, when $y_{0}<r_{b}$, the expected profit from the working capital mode is higher, the buyer should adopt the working capital method to make early payments to suppliers. When $y_{0} \geq r_{b}$, the buyer should adopt short-term debt. The buyer's profit must also be greater than zero; that is, the buyer also makes a profit, resulting in an incentive for both parties to reach an early payment agreement. When working capital is used for early payment, $\pi_{b_{-} w}$ should not be less than zero, which is a concave function passing through the origin. Therefore, this study needs to discuss the symmetry axis of $\pi_{b_{-} w}$. Provided that $\operatorname{ep}(\tilde{t})$ is set as the symmetry axis, if $0 \leq e p(\tilde{t})<G / 2$ (i.e., $\left.y_{0} /\left(1+y_{0} \cdot G\right)<d d_{2} \leq y_{0}\right)$, a different payment period will affect the buyer's profit. The early period, when the buyer's profit is greater than zero, is from $\left(y_{0}-d d\right) / d d \cdot y_{0}$ to $G$; if ep $\left.\widetilde{t}\right) \leq 0\left(d d_{2} \geq y_{0}\right)$, the buyer's profit is greater than zero at any time. Therefore, if the buyer uses working capital for early payment, the daily discount rate should satisfy $d d_{2}>y_{0} /\left(1+y_{0} \cdot G\right)$ to ensure the possibility that the buyer's profit is greater than zero. Overall, when $y_{0}<r_{b}$, the $d d$ provided by the supplier should satisfy Eq. (18)

$$
y_{0} /\left(1+y_{0} \cdot G\right)<d d_{2} \leq r_{s} /\left(r_{s} \cdot G+1\right)
$$


When $y_{0} \geq r_{b}$, the buyer should choose short-term debt to pay early, and the proof is the same as above; hence the following conclusion equation is reached.

$$
r_{b} /\left(1+r_{b} \cdot G\right)<d d_{2} \leq r_{s} /\left(r_{s} \cdot G+1\right)
$$

For suppliers, when the reasonable range of daily discount rate is determined, they need to further promote the DD program based on limited information. Moreover, according to the previous review, the role of the FIMP is to create a fair and equal environment for SMEs and try to balance the profits of the supply and demand parties, so that they can obtain more equal capital income. Therefore, based on the FIMP, suppliers need to consider the expected profits of both sides when setting the discount rates. This means that when $\Pi_{b}=\Pi_{s}$, the difference in the profits of both sides is minimal, the FIMP promotes the maximum realization of profit sharing, and both parties are willing to accept the discount rate. Currently, the discount rate is the optimal discount rate. Specifically, if $y_{0}<r_{b}$, the buyer will use working capital for early payment. The buyer's profit expectation function is shown in Eq. (10) and the supplier's profit expectation function is shown in Eq. (12). Assuming equal profit between the two parties, the optimal daily discount rate for both parties can be solved for using Eq. (20):

$$
d d_{2}^{*}=\frac{3 \cdot\left(r_{s}+y_{0}\right)}{6+r_{s}+2 G \cdot r_{s}+y_{0}+2 G \cdot y_{0}}
$$

Similarly, if $y_{0} \geq r_{b}$, the buyer will incur short-term debt to pay; accordingly, the buyer's profit expectation function is described in Eq. (11). Assuming equal profits between the two parties again, it can be concluded that the daily discount rate is as stated in Eq. (21).

$$
d d_{2}^{*}=\frac{3 \cdot\left(r_{b}+r_{s}\right)}{6+r_{b}+2 G \cdot r_{b}+r_{s}+2 G \cdot r_{s}}
$$

Based on the analysis of the range of discount rate and the value of the optimal discount rate, Proposition 1 is obtained.

Proposition 1 For suppliers, when $y_{0}<r_{b}$, the daily discount rate offered should satisfy $\frac{y_{0}}{1+y_{0} \cdot G}<d d_{2} \leq \frac{r_{s}}{1+r_{s} \cdot G}$, and the optimal daily discount rate shall be $d d_{2}^{*}=\frac{3\left(r_{s}+y_{0}\right)}{6+r_{s}+2 G \cdot r_{s}+y_{0}+2 G \cdot y_{0}}$; when $y_{0} \geq r_{b}$, the daily discount rate should satisfy $\frac{r_{b}}{1+r_{b} \cdot G}<d d_{2} \leq \frac{r_{s}}{1+r_{s} \cdot G}$, and the optimal daily discount rate shall be $d d_{2}^{*}=\frac{3\left(r_{b}+r_{s}\right)}{6+r_{b}+2 G \cdot r_{b}+r_{s}+2 G \cdot r_{s}}$.

It follows that, when the supplier offers a discount rate that satisfies $d d_{2}^{*}<d d_{2} \leq$ $r_{s} /\left(r_{s} \cdot G+1\right)$, the buyer will generate more profit than the supplier. Contrarily, if $y_{0} /\left(y_{0} \cdot G+1\right)<d d_{2}<d d_{2}^{*}$ or $r_{b} /\left(r_{b} \cdot G+1\right)<d d_{2}<d d_{2}^{*}$, the supplier will generate more profit than the buyer.

Through Proposition 1, it can be concluded that the supplier can provide $d d^{*}$ to predict the discount rate that the buyer is most likely to accept, and then enhance the buyer's motivation for early payment. According to the traditional DD model, it can be concluded that the buyer may have insufficient working capital and the FIMP will provide short-term bank financing; therefore, the buyer should balance the allocation of funds from different sources (working capital and funds from financial institutions) simultaneously when there is a funds shortage. Therefore, how the buyer should optimize multiple sources of funds to complete the DD program is analyzed. 
(2) Working capital constraints liq $_{2}$ As an increasing number of suppliers hope to get accounts receivable in advance through the DD program, the FIMP will provide more capital sources for the buyer, so that the buyer can make full use of various capital combinations. The buyer can choose either working capital or short-term debt to pay for a discount but in advance, based on the relation between $y_{0}$ and $r_{b}$. According to the above analysis, when $y_{0}<r_{b}$, no matter when to fulfill the early payment, expected profit of working capital mode is higher; thus, the buyer should adopt the working capital method to adopt early payments to suppliers; when $y_{0} \geq r_{b}$, they should use short-term debt. Concurrently, the buyer will encounter sufficient and insufficient working capital.

If $y_{0}<r_{b}$ and buyer's working capital is insufficient, that means $l i q_{2}<N \cdot v_{n}$; this study sets $l i q_{\max }=N \cdot v_{n}$. The threshold for the buyer's working capital, $l i q_{C}$, is set as the minimum amount $\left(N \cdot v_{n} \cdot[1-d d \cdot G]\right)$ that the buyer needs to prepare if early payment of all the suppliers is planned. When the actual amount of working capital satisfies $l i q_{C} \leq l i q_{2}<l i q_{\max }$ it means that, although the buyer can use working capital for early payment, the payment ability is affected by the specific time and discount rate. Then, a critical value of $e p(t)_{L}$ is set if the buyer uses working capital to pay all suppliers; $e p(t)_{2}$ needs to at least exceed ep(t) $)_{L}$, so ep $(t)_{L}=\left(N \cdot v_{n}-l i q\right) /\left(N \cdot v_{n} \cdot d d\right)$ is obtained. The buyer can only choose the payment method freely at this time, when ep $(t)$ is in the range of $\left[\operatorname{ep}(t)_{L}, G\right]$. As the rational buyer will choose a more profitable method, working capital will be used for early payment. When $e p(t)_{2}$ is within the range of $\left[0, e p(t)_{L}-1\right]$, if the buyer wants to use working capital to pay all suppliers, the working capital is likely to be insufficient. Thus, when $\operatorname{ep}(t)_{2} \in\left[0, \operatorname{ep}(t)_{L}-1\right]$, and $N_{1}\left(N_{1}<N\right)$ are the number of suppliers that the buyer can pay early from working capital while the remaining suppliers $N-N_{1}$ are paid using short-term debt, the buyer's profit is shown in Eq. (22).

$$
\begin{aligned}
& \underset{\substack{y_{0}<r_{b}, l i q_{C} \leq l i q<l i q_{\max } \\
\Pi_{b 2_{2} w d}}}{G} \theta \cdot N \cdot v_{n} \cdot d d \cdot e p(t) \\
& -\sum_{e p(t)_{2}=e p(t)_{L}}^{G} \theta \cdot N \cdot v_{n} \cdot y_{0}[1-d d \cdot e p(t)] \cdot e p(t) \\
& -\sum_{e p(t)_{2}=0}^{e p(t)_{L}-1} \theta \cdot N_{1} \cdot v_{n} \cdot y_{0}[1-d d \cdot e p(t)] \cdot e p(t) \\
& -\sum_{e p(t)_{2}=0}^{e p(t)_{L}-1} \theta \cdot\left(N-N_{1}\right) \cdot v_{n} \cdot r_{b}[1-d d \cdot e p(t)] \cdot e p(t)
\end{aligned}
$$

If $l i q_{2}<l i q_{C}$, the buyer cannot fulfill payment to all suppliers using working capital, at any time; thus, only some suppliers can be paid with working capital, and the rest through short-term debt. The buyer's profit under these circumstances is shown in Eq. (18). According to the above analysis, when $y_{0}<r_{b}$, the buyer's profit is greater when paying by working capital than when using short-term debt. When $0 \leq l i q_{2}<l i q_{C}$, less working capital will be utilized in payment, so the result obtained from Eq. (22) is evidently larger than that of Eq. (23). 


$$
\begin{aligned}
& \begin{array}{l}
\Pi_{b 2 \_w d} \\
y_{0}<r_{b}, 0 \leq l i q<l i q_{C} \\
\end{array}=\sum_{t=0}^{G} \theta \cdot N \cdot v_{n} \cdot d d \cdot e p(t) \\
& -\sum_{e p(t)_{2}=0}^{G} \theta \cdot N_{1} \cdot v_{n} \cdot y_{0}[1-d d \cdot e p(t)] \cdot e p(t) \\
& -\sum_{e p(t)_{2}=0}^{G} \theta \cdot\left(N-N_{1}\right) \cdot v_{n} \cdot r_{b}[1-d d \cdot e p(t)] \cdot e p(t)
\end{aligned}
$$

In view of the situation that the buyer's working capital is insufficient, and the mixed method of payment must be used, it is necessary to consider whether the buyer's expected profit could be less than zero under this payment method. Therefore, the possibility that Eq. (23) could return a result less than zero is analyzed. When the buyer's expected profit is zero, the value of working capital is $l i q_{2}^{\min }$, from Eq. (24). At this time, if $d d_{2}<3 r_{b} /\left(3+r_{b}+2 G \cdot r_{b}\right)$, then $l i q_{2}^{\min }>0$, and the buyer needs to prepare funds to the value of at least $l i q_{2}^{\min }$ to ensure that the expected profit is not less than zero. If $d d \geq 3 r_{b} /\left(3+r_{b}+2 G \cdot r_{b}\right)$, then $l i q_{2}^{\min } \leq 0$, and any amount of the buyer's working capital can ensure that the buyer's profit expectation is not less than zero.

$$
l i q_{2}^{\min }=\frac{N \cdot v_{n} \cdot\left(3 r_{b}-3 d d-d d \cdot r_{b}-2 d d \cdot G \cdot r_{b}\right)}{3\left(r_{b}-y_{0}\right)}
$$

This study further analyzes the maximum profit expectation of the buyer's mixed payment method. As the optimal amount of $l i q_{2}$ is obtained through Eq. (22), it is necessary to derive it and make the derivative equal to zero to get the optimal amount $l \hat{i} q$, as stated in the following:

$$
l \hat{i} q_{2}=N \cdot\left(v_{n}-\sqrt{3} \cdot d d \cdot v_{n}\right)
$$

If $y_{0} \geq r_{b}$, seller payments using short-term debt will create more profits for the buyer at any time in the invoice cycle. If the buyer chooses to use working capital for payment, part of the profit will be forfeited. Therefore, a rational buyer does not need to arrange any working capital assuming that the buyer will not use the mixed payment method in this situation, regardless of their inability to obtain debt from a third party. The buyer's profit remains as shown in Eq. (11). It means that the buyer does any working capital requirements in this situation, that is, the optimal and minimum amount of working capital is zero.

Therefore, this study proposes Proposition 2, wherein the buyer's optimal working capital strategy and the resultant profit changes are analyzed.

\section{Proposition 2}

(1) If $y_{0}<r_{b}$ and the buyer's working capital is insufficient (li $\left.q_{2}<N \cdot v_{n}\right)$, the buyer needs to use mixed funding sources to settle invoices early. When the daily discount rate provided by the supplier satisfies $d d_{2}<\frac{3 \cdot r_{b}}{3+r_{b}+2 G \cdot r_{b}}$, the buyer's working capital needs to exceed the amount of $\frac{N \cdot v_{n} \cdot\left(3 r_{b}-3 d d-d d \cdot r_{b}-2 d d \cdot G \cdot r_{b}\right)}{3\left(r_{b}-y_{0}\right)}$ at least to ensure that the buyer's expected profit is not less than zero; when $d d_{2} \geq \frac{3 \cdot r_{b}}{3+r_{b}+2 \cdot G \cdot r_{b}}$, any amount of buyer's working capital will ensure that the expected profit of the mixed payment method is not less than zero. When the buyer makes working capital of $N$. 
$\left(v_{n}-\sqrt{3} \cdot d d \cdot v_{n}\right)$ available in the mixed payment method, their expected profit can be maximized.

(2) If $y_{0} \geq r_{b}$, the buyer should use short-term debt for early payment, and the optimal amount of working capital is zero.

In the light of the above analysis, suppliers can determine a range of daily discount rates and an precise daily discount rate, to enhance the buyer's possibility of DD adoption and to alleviate the problem of capital shortages. For the buyer, a capital combination can be chosen more freely, and a mixed payment method can be employed to optimize the use of working capital, to improve their own capital income.

However, from the above analysis, it is found that the determinants of discount rate and the allocation buyer's funds are still based on an uncertain early payment period. As the buyer has multiple suppliers and individual business-to-business communication is required, huge costs are incurred. Therefore, the specific payment period cannot be determined. If the buyer's payment period is not set, there may be greater uncertainty for both parties which results in missing the optimal payment period. Thus, some suppliers do not receive advanced payment. Therefore, to address the difficulty of determining the optimal payment period, the third part is defined as follows.

(3) Early payment period ep $(t)_{2}$ The FIMP can provide a settlement transaction environment for both parties to automatically trigger an optimal early payment period. Furthermore, it can help improve the settlement efficiency for both parties in the DD model, and help SMEs address the problem of uncertain payment period. In practice, C2FO, Demica and other enterprises use the FIMP to integrate capital requirements of suppliers of various sizes into an invoice pool. Then, FIMP determines a basic profit level based on the historical orders of the core enterprise and order information in the invoice pool (Demica 2007). Although this method will lead to profit spillover for the buyer, it will also help the buyer save significant transaction costs, activate entire supply chain, and improve the efficiency of invoice processing. Therefore, the decision-making of FIMP-based DD program has a premise of meeting the buyer's basic profit level requirements, and the suppliers determine the discount rate and payment period when their profit level is the highest.

According to Eq. (9), the suppliers' expected profit function is a convex curve, and its symmetry axis satisfies $e p(\tilde{t})_{s}=1 /(2 d d)-1 /\left(2 r_{s}\right)$. If $0<e p(\tilde{t})_{s}<G\left(d d>\frac{r_{s}}{2 G \cdot r_{s}+1}\right)$, the payment period corresponding to the maximum $\Pi_{s}$ is $\operatorname{ep}(t)_{2}^{*}=1 /(2 d d)-1 /\left(2 r_{s}\right)$, and if $\operatorname{ep}(\tilde{t})_{s} \geq G\left(d d \leq \frac{r_{s}}{2 G \cdot r_{s}+1}\right)$, the payment period corresponding to the maximum $\Pi_{s}$ is $e p(t)_{2}^{*}=G$. Therefore, Proposition 3 is proposed to determine the optimal early payment period decision of the DD program based on FIMP in different situations.

Proposition 3 If $\frac{r_{s}}{2 G \cdot r_{s}+1}<d d_{2}<\frac{r_{s}}{G \cdot r_{s}+1}$, the optimal payment period satisfies $e p(t)_{2}^{*}=\frac{1}{2 d d}-\frac{1}{2 r_{s}}$; if $y_{0}<r_{b}$ and $\frac{y_{0}}{G \cdot y_{0}+1}<d d_{2} \leq \frac{r_{s}}{2 G \cdot r_{s}+1}$ or $y_{0} \geq r_{b}$ and $\frac{r_{b}}{G \cdot r_{b}+1}<d d_{2} \leq \frac{r_{s}}{2 G \cdot r_{s}+1}$, the optimal payment period satisfies ep $(t)_{2}^{*}=G$.

Currently, the maximum profit function of each supplier is expressed as Eq. (26), and the maximum profit function of all suppliers is given in Eq. (27). The buyer must necessarily consider whether to use working capital or short-term debt for early payment. If $y_{0}<r_{b}$, the 


\begin{tabular}{ll}
\hline Parameter & Value assumed \\
\hline$G$ & 90 days \\
$v_{n}$ & $250000 €$ \\
$r_{b}$ & $0.0053 \%$ \\
$r_{s}$ & $0.0276 \%$ \\
$N$ & 200 \\
$\theta$ & $1 / 90$ \\
\hline
\end{tabular}

buyer should choose working capital, and if $y_{0} \geq r_{b}$, short-term debt should be used. The maximum profit function of the buyer is shown in Eq. (28).

$$
\begin{aligned}
& \max \pi_{s 2}=-v_{n} \cdot d d_{2} \cdot r_{s} \cdot e p(t)_{2}^{* 2}+v_{n} \cdot\left(r_{s}-d d_{2}\right) \cdot e p(t)_{2}^{*} \\
& \max \Pi_{s 2}=N \cdot v_{n} \cdot\left[1-d d_{2} \cdot e p(t)_{2}^{*}\right] \cdot e p(t)_{2}^{*} \cdot r_{s}-N \cdot v_{n} \cdot d d_{2} \cdot e p(t)_{2}^{*} \\
& \max \Pi_{b 2}=\left\{\begin{array}{c}
N \cdot v_{n} \cdot d d_{2} \cdot e p(t)_{2}^{*}-N \cdot v_{n} \cdot\left[1-d d_{2} \cdot e p(t)_{2}^{*}\right] \cdot e p(t)_{2}^{*} \cdot r_{b} \\
y_{0} \geq r_{b} \\
N \cdot v_{n} \cdot d d_{2} \cdot e p(t)_{2}^{*}-N \cdot v_{n} \cdot\left[1-d d_{2} \cdot e p(t)_{2}^{*}\right] \cdot e p(t)_{2}^{*} \cdot y_{0} \\
y_{0}<r_{b}
\end{array}\right.
\end{aligned}
$$

In sum, from the analysis, it can be concluded that FIMP can help DD participants bring the following potential benefits: (1) FIMP can collect the buyer's working capital cost and other information in advance, help suppliers more accurately formulate a reasonable range of discount rates, and improve the possibility of SMEs obtaining early payment through the DD program. (2) It facilitates a fair communication channel for SMEs, thereby promoting agreements on DD schemes while balancing their profits. (3) It provides multiple sources of capital for the buyer that can effectively serve suppliers' diversified working capital requirements. (4) It can help both the suppliers and the buyer set an optimal early payment period in advance to improve the profit of both parties and the efficiency of the DD program.

\section{Numerical example and sensitivity analysis}

Input data and parameters for the analysis have been gathered from interviews, secondary sources, and experts (Gelsomino et al. 2016b; Gelsomino et al. 2019). Table 1 illustrates the value assumed by the different parameters required to run the model. A reliable estimation of its payment term is 90 days (i.e., $\mathrm{G}=90)$. The value $\left(v_{n}\right)$ of each invoice issued by the supplier to the buyer is $250,000 €$. The initial liquidity is set at the maximum, $l i q=N \cdot v_{n}$. The financial third party's short-term debt rate $r_{b}$ is $0.0053 \%$. The supplier's financing cost per unit of currency $r_{s}$ is $0.0276 \%$, and $r_{b}<r_{s}$. The number of suppliers is 200 . The buyer has an equal probability $\theta$ of payment at each time $t$, so $\theta=1 / 90$. All parameters are shown in Table 1. In the process of numerical examples and sensitivity analysis, the differences in discount rate setting, working capital contract, and optimal early payment period between the traditional DD model and the DD model based on FIMP are compared.

(1) Discount rate $d d$ If $y_{0}<r_{b}, y_{0}=0.0023 \%$ is set in the traditional DD model, as the suppliers cannot get the buyer's capital cost, the discount rate can only be set based on their own positive profit and $0<d d_{1} \leq 0.0269 \%$. It means that if the discount rate provided by the suppliers is $0<d d_{1}<0.0229 \%$, the buyer's profit will be negative; 
Table 2 Effect of different dd values on the profit expectations of the buyer and suppliers

\begin{tabular}{lll}
\hline$d d(\%)$ & $\begin{array}{l}\text { Buyer's profit } \\
\text { expectation }(€)\end{array}$ & $\begin{array}{l}\text { Suppliers' profit } \\
\text { expectation }(€)\end{array}$ \\
\hline 0.0015 & -18152.6 & 593207.0 \\
0.0020 & -6761.8 & 581642.3 \\
0.0023 & 0 & 574704.3 \\
0.0058 & 79808.1 & 493753.6 \\
0.0067 & 100312.3 & 472937.7 \\
0.0089 & 150431.4 & 422053.3 \\
0.0111 & 200550.4 & 371170.4 \\
0.0136 & 257504.2 & 313348.7 \\
0.0148 & 284842.2 & 284842.2 \\
0.0193 & 387359.6 & 181514.3 \\
0.0223 & 455704.4 & 112127.8 \\
0.0256 & 530883.5 & 35801.9 \\
0.0268 & 558221.1 & 8047.3 \\
0.0271 & 5372442.8 & 0 \\
\hline
\end{tabular}

consequently, the buyer will directly refuse the suppliers' application for DD. In a DD program based on FIMP, according to Proposition 1, $0<d d_{2} \leq 0.0269 \%$ is obtained. According to Eq. (15), the optimal daily discount rate $d d_{2}^{*}$ provided by the suppliers is $0.0148 \%$. If $d d_{2}>d d_{2}^{*}$, the buyer's profit increases while that of the supplier decreases. Contrariwise, if $d d_{2} \leq d d_{2}^{*}$, the buyer's profit decreases and that of the supplier increases. In addition, dd cannot be increased or decreased infinitely. The minimum value of $d d$ is $0.00229 \%$, and the maximum is $0.0269 \%$. The profit expectation corresponding to different rates of $d d$ is shown in Table 2, which indicates that the discount rate needs to be set within a specific range. The discount rate will be optimal only when their profits are equal, as each side will have a high tendency to reach an agreement. Compared with the traditional model, the range of discount rates based on FIMP is more accurate, which can ensure the buyer is willing to participate in DD. Concurrently, the optimal discount rate will further promote the settlement of the DD program. Moreover, if $y_{0} \geq r_{b}$, the situation is similar to the above analysis.

In the traditional model, the buyer can only utilize their own capital for early payment, while in the FIMP model, the buyer has multiple sources of capital. The two models are identical when the buyer's capital is sufficient; however, increasingly suppliers are adopting DD while the buyer's own capital is limited, and thus, the FIMP-based model can better solve the above problems by providing more sources.

(2) Working capital constraints liq In the traditional model, the buyer has signal source of capital. Therefore, when increasing suppliers apply DD, the buyer needs to prepare more funds. This study verifies the main differences between the two models when the buyer's capital is sufficient or insufficient.

First, it is assumed that $y_{0} \leq r_{b}, y_{0}=0.0023 \%$, and $d d^{*}=0.0148 \%$. When the working capital is sufficient, the profit for all suppliers will be higher. Therefore, the traditional model and the FIMP model are identical. The expected profit of both parties is $284,842.2 €$, as calculated through Eq. (10). 


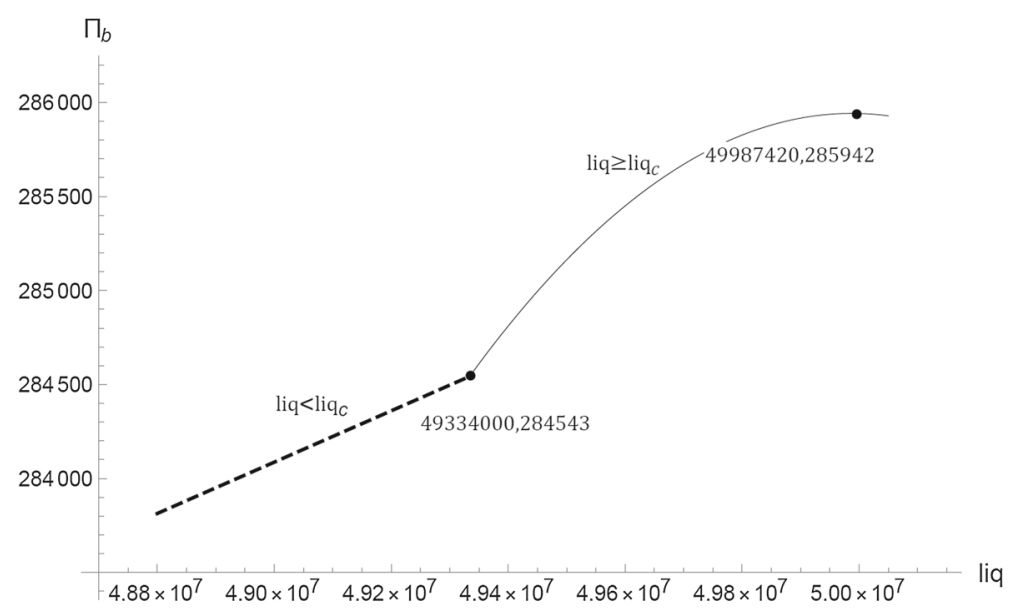

Fig. 1 Relationship between the buyer's working capital and profit

If buyer's working capital is insufficient, the buyer needs to arrange at least 49,334,000€as shown in Eq. (14) under the traditional model, and the expected profit is $6,265.3 €$. If the same expected profit is obtained from the FIMP model, only 43,500,300€working capital is required and 5,833,700€is saved. However, in traditional models, working capital cannot be lower than 49,334,000€. In the FIMP model, as $d d^{*} \geq 3 r_{b} /\left(3+r_{b}+2 G \cdot r_{b}\right)=0.00528 \%$ is known, there would be no possibility that the buyer's expected profit is less than zero, even though there is insufficient working capital. Therefore, the buyer's minimum amount of working capital is $0 €$. According to Eq. (25), when the buyer's working capital satisfies $N \cdot\left(v_{n}-\sqrt{3} \cdot d d \cdot v_{n}\right)$ (equal to $49,987,420 €$ ), the maximum expected profit of the buyer is $285,942 €$, which saves $12,580 €$ working capital compared with $l i q_{\max }$, and higher profit expectations can be achieved (compared to 284,842€). If the amount of working capital is zero, the buyer can only choose short-term debt for early payment. According to Eq. (22), the expected profit is $217,202 €$. Compared with the traditional model, the amount of working capital reduced significantly (from 49,334,000€ to $0 €$ ), and the expected profit increased significantly (from 6,265.3€to $217,202 €$ ). Therefore, when $d d^{*}$ is equal to $0.0148 \%$, according to Eqs. (17) and (18) and different working capital amounts, Fig. 1 shows the change of expected profit achieved by different amounts of working capital when the buyer uses the mixed repayment method. It is evident from Fig 2 that, if the buyer sets the working capital in a reasonable range, the expected profit level can be improved accordingly.

In addition, a sensitivity analysis on the working capital amount and discount rate based on the FIMP model is conducted. When the discount rate changes, the buyer's expected profit may be negative. As shown in Fig. 2, if the discount rate is in the range of 0.000022968 to 0.000052831 , the buyer's working capital should be at least $N \cdot v_{n}\left(3 r_{b}-3 d d-d d \cdot r_{b}-2 d d \cdot G \cdot r_{b}\right) /\left[3\left(r_{b}-y_{0}\right)\right]$. Only when the working capital is greater than this value can the buyer's profit expectation be positive. Therefore, the buyer needs to reasonably arrange the use of working capital based on the specific discount rate to avoid generating negative expected profit.

Second, it is assumed that $y_{0}>r_{b}$, and $d d^{*}=0.0148 \%$. In this situation, in the traditional model, the minimum working capital is $l i q_{C}$. In the FIMP model, the buyer can replace all the working capital with short-term debt, and the minimum amount of working capital for 


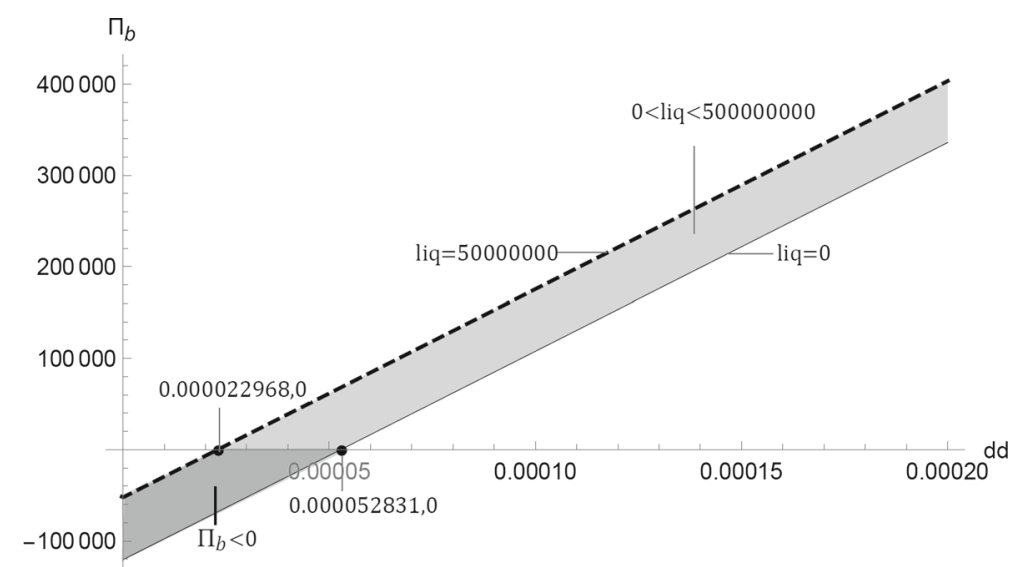

Fig. 2 Relationship between $d d$ and buyer's profit

the buyer will be reduced to zero. At this time, the advantage of the FIMP model is evident. It can not only save more working capital but also incur short-term debt with lower cost to the DD program; thus, the profit will also be significantly higher than in the traditional DD model.

(3) Early payment period ep ( $t$ ) In the traditional DD model, the suppliers do not know the buyer's specific early payment period accurately but can only know their payment period range $\left[\operatorname{ep}(t)_{L}, G\right]$; thus, the payment period is uncertain, and only the expected profit can be measured on both sides. However, in the FIMP model, the platform can help the participants to determine the optimal early payment period by pre-setting parameters in advance. The following is to verify the sensitivity of early payment period in FIMP model under $y_{0} \leq r_{b}$ and $y_{0}>r_{b}$ conditions.

When $y_{0} \leq r_{b}, y_{0}=0.0023 \%$ and $d d^{*}=0.0148 \%$ as above, and $d d^{*}$ is satisfied $d d^{*}<r_{s} /\left(2 G \cdot r_{s}+1\right)$. In the FIMP model, it can be calculated that the optimal payment period is (equal to 90 days), and the buyer's profit with the working capital method is higher. According to Eqs. (27) and (29), it can be calculated that: $\max \Pi_{s}=559,456.55 €$, $\max \Pi_{b}=563,878.62 €$. If the working capital is not sufficient (reduced to the minimum value of zero), the buyer will use alternative payment methods through short-term debt; at this time, $\max \Pi_{b}=430,677 €$, and suppliers' profit is unchanged. In the traditional model, when the working capital is sufficient, the profit of the buyer and the suppliers can only be calculated by the expected profit, which is $284,842 €$. If the working capital of the buyer is reduced to $\left(l i q_{C}\right)$, then the expected profit of the supplier and the buyer is only $6,265 €$. Through comparative analysis, it can be concluded that the profit at an optimal early payment period will be higher than that in the traditional DD model, which means that when the FIMP can help the participants to determine the specific payment period, their profits will be further improved, as shown in Figs. 3 and 4 .

To further verify the sensitivity of the discount rate, $y_{0}$ and $r_{b}$ are set as $0.0260 \%$ and $0.0261 \%$, respectively, and $d d^{*}=0.02637 \%$ is calculated based on Eq. (20); at this time $d d^{*}$ is satisfied $d d^{*} \geq r_{s} /\left(2 G \cdot r_{s}+1\right)$. In FIMP model, according to Proposition 3 , the optimal payment period ep $(t)^{*}$ is equal to $1 /\left(2 d d^{*}\right)-1 /\left(2 r_{s}\right)$, which equates to an integer of 84 days. At this time, if the buyer has sufficient working capital, the maximum profits of both parties can be calculated as: $\max \Pi_{b}=397,288 €$, and $\max \Pi_{s}=25,983 €$, respectively. 


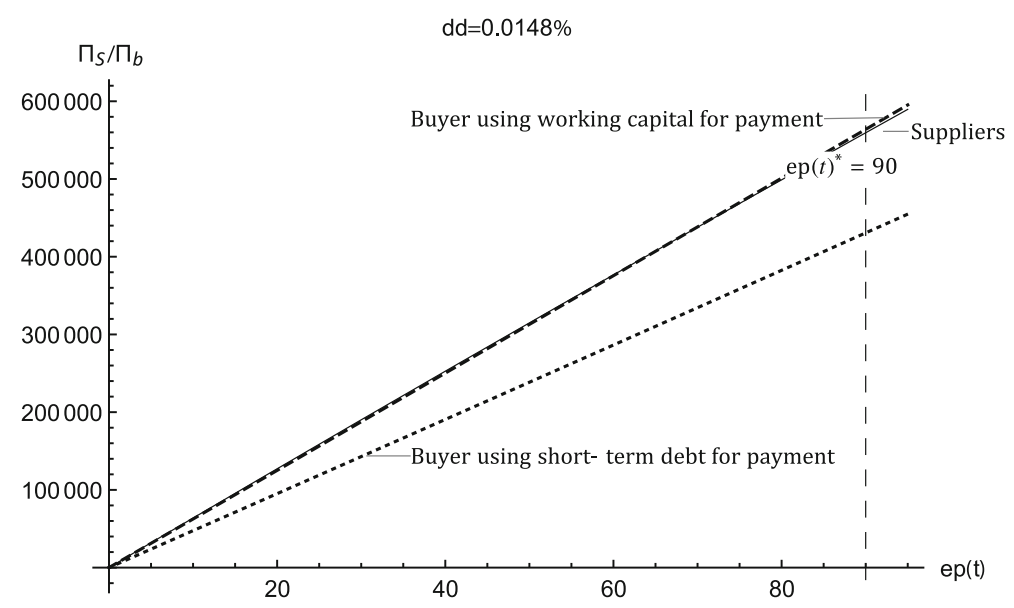

Fig. 3 Influence of different payment periods on profits when $d d^{*}$ is less than $r_{S} /\left(2 G r_{s}+1\right)$ and $y_{0}$ is no more than $r_{b}$

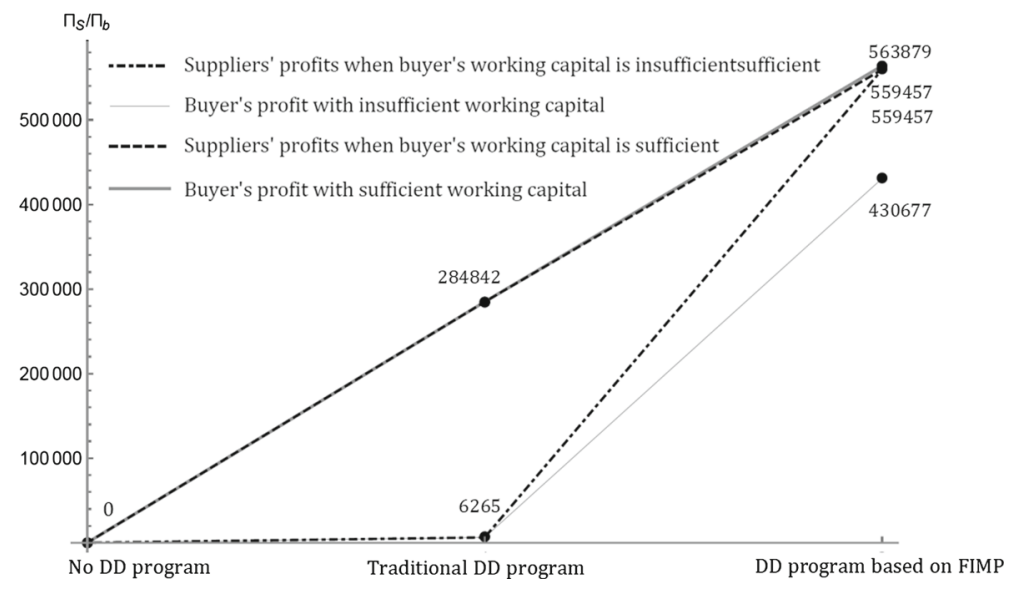

Fig. 4 Influence of buyer's working capital amount and different payment strategies on profits when $d d^{*}$ is less than $r_{s} /\left(2 G r_{s}+1\right)$ and $y_{0}$ is no more than $r_{b}$

If the buyer has insufficient working capital, the worst position for them to be is where the payment needs to be replaced by short-term debt. Then, the buyer's maximum profit is $\max \Pi_{b}=35,622 €$ and the profits of suppliers remain unchanged, $\max \Pi_{s}=25,983 €$. In the traditional DD model, when the buyer's working capital is sufficient, the expected profit of the buyer and the supplier are both 17,858€. If the buyer's working capital is insufficient, the expected profit for them is further reduced to $494 €$. In this situation, in the FIMP model, the optimal early payment period changes, and the profit of the buyer and the supplier in the FIMP-based model is also higher than that in the traditional model, as shown in Figs. 5 and 6 .

Next, it is given that $y_{0}>r_{b} ; y_{0}$ and $r_{b}$ are $0.0272 \%$ and $0.0263 \%$, respectively; then $d d^{*}=0.02665 \%$, and at this point, $d d^{*}$ is satisfied as $d d^{*} \geq r_{s} /\left(2 G \cdot r_{s}+1\right)$. According to Proposition 3, the optimal payment period in FIMP model satisfies ep $(t)^{*}=1 /\left(2 d d^{*}\right)-$ $1 /\left(2 r_{s}\right)$ (73.71 days), a result that can be rounded to an integer of 74 days. In this situation, 


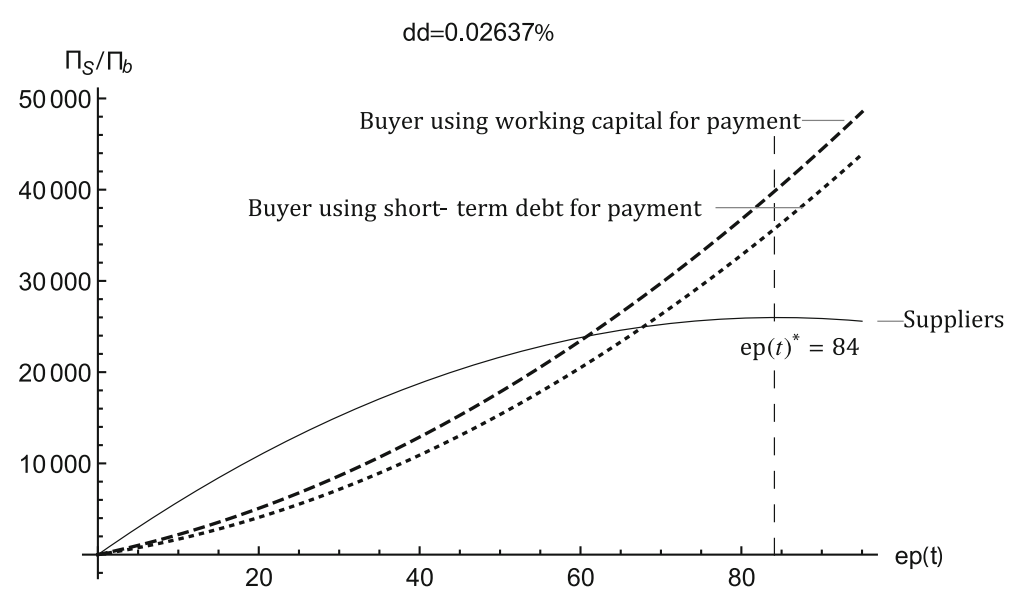

Fig. 5 Influence of different payment periods on the profits when $d d^{*}$ is no less than $r_{s} /\left(2 G r_{s}+1\right)$ and $y_{0}$ is no more than $r_{b}$

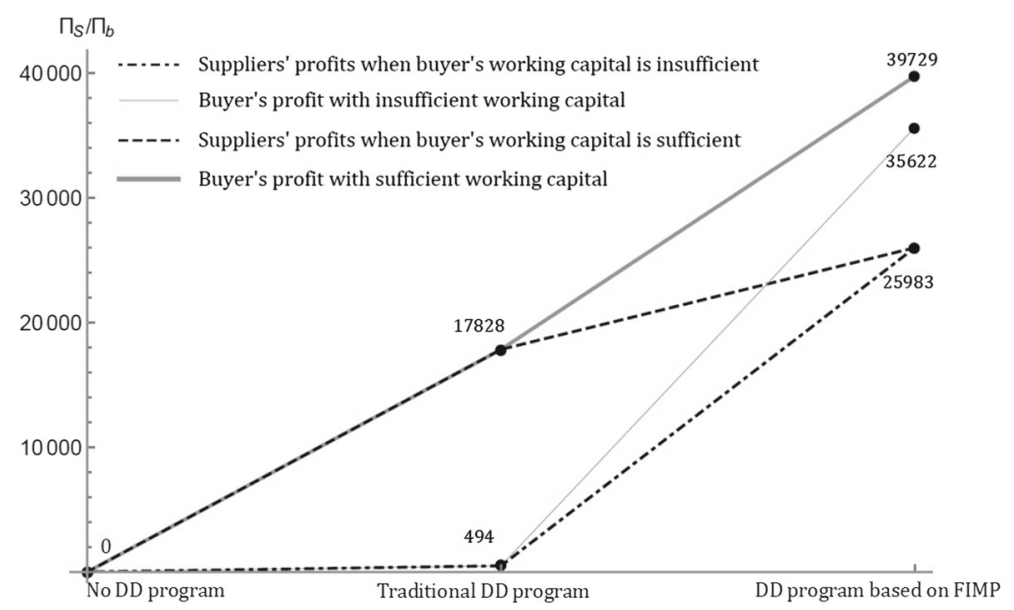

Fig. 6 Influence of buyer's working capital amount and different payment strategies on profits when $d d^{*}$ is no less than $r_{s} /\left(2 G r_{s}+1\right)$ and $y_{0}$ is no more than $r_{b}$

the buyer will incur short-term debt to make payment; thus, the buyer's maximum profit will be equal to $27,237 €$, and the suppliers' maximum profit will be unchanged at $19,919 €$. In the traditional model, the buyer will reject the suppliers' application, and their profit will be $0 €$, regardless of whether the buyer's working capital is sufficient. Therefore, only the DD based on FIMP can improve the profits of both parties, while the traditional DD model may result in buyers forgoing opportunities for profit, as shown in Figs. 7 and 8.

From the above analysis, it can be concluded that the DD program will greatly improve the payment period and capital turnover cycle of the participants. The results of the numerical example show that the improvement of the important parameters of the DD program (the daily discount rate, the working capital payment method, and the optimal payment period) on the profits have been verified. The conclusions in the propositions are consistent with the reality. Therefore, as for the suppliers, the DD program based on FIMP will enhance their 


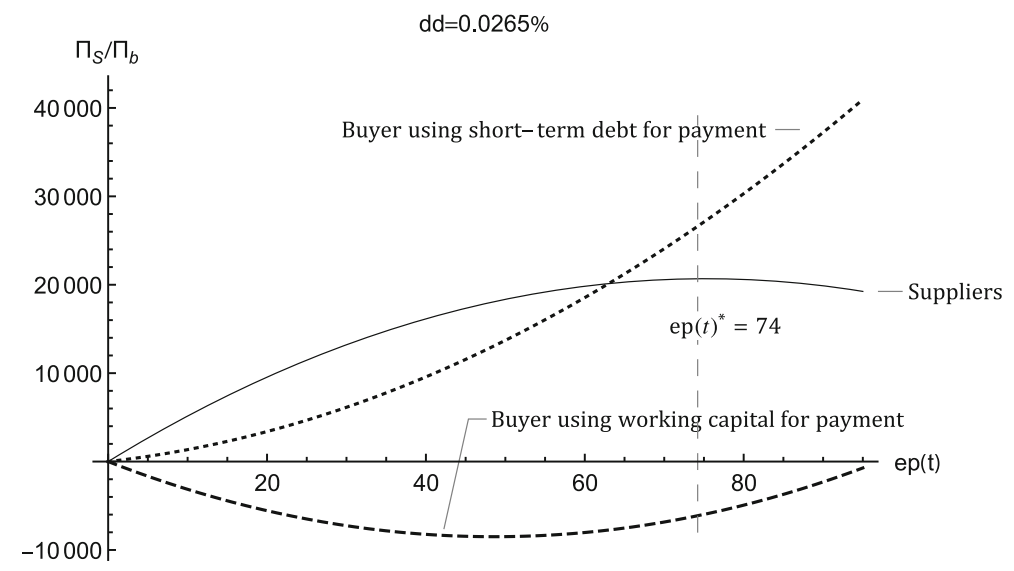

Fig. 7 Influence of different payment periods on the profits when $d d^{*}$ is no less than $r_{s} /\left(2 G r_{s}+1\right)$ and $y_{0}$ is more than $r_{b}$

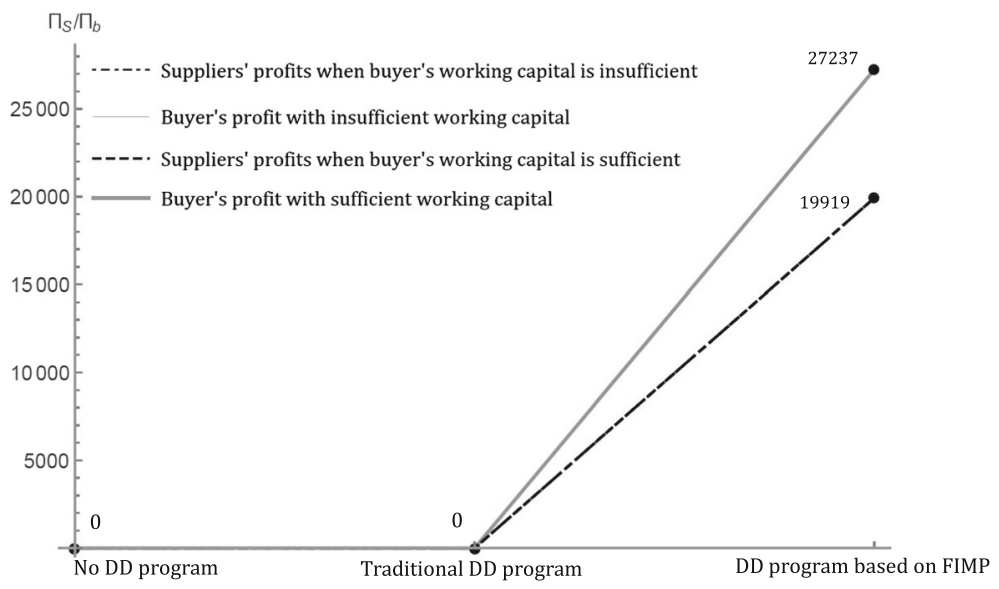

Fig. 8 Influence of buyer's working capital amount and different payment strategies on profits when $d d^{*}$ is no less than $r_{s} /\left(2 G r_{s}+1\right)$ and $y_{0}$ is more than $r_{b}$

motivation to participate, especially for enterprises with low profit margins; thus, they can mitigate the impact of insufficient operating funds by joining the DD platform. By choosing a different payment period and working capital reserve, the buyer can effectively improve cash flow and reduce capital cost.

\section{Conclusion, insights, and future research direction}

\subsection{Conclusion}

The DD model is a new approach of SCF, which can solve the problem of working capital shortage of SMEs from the perspective of capital efficiency optimization. This study established an analysis model to explore the impact of FIMP on the DD model. Specifically, first, 
decision-making in the traditional DD model (peer-to-peer situation) and that in the FIMPbased DD model were compared and analyzed. Second, this study calculated the range of discount rate and an optimal discount rate to promote the two parties' willingness to use DD settlement, and the buyer's working capital optimization schemes and an optimal payment period were subsequently derived.

By comparing the two types of DD models, this study revealed the mechanisms of the FIMP on DD program participants' capital profits. This study found that, compared with the traditional model, the DD program based on FIMP can provide information such as the buyer's capital cost and supplier quantity, and other key information; subsequently, SME suppliers can arrive at a more accurate range of discount rate and the optimal daily discount rate. Furthermore, the FIMP can also provide more sources of funds for the buyer and enhance the possibility of the buyer to find an optimal capital portfolio to meet more dynamic discount requirement. The FIMP can also provide the suppliers and buyer a settlement transaction environment that automatically triggers the optimal early payment period, further improve the settlement efficiency of the DD model, and create a win-win situation for both parties. Therefore, this study drew noteworthy conclusions through modeling DD decisions.

Considering the analyses, it was discovered that the discount rate provided by the suppliers should be set within a reasonable range. If the discount rate is too high or too low, the early settlement motivation of one party and the profits of both parties will be reduced. Therefore, the profit level of both parties can be improved by comparing the standard payment terms. This study also found that the buyer's should have the minimum optimal amount of working capital in the DD program after considering different discount rate values. The proportion of self-owned capital and banks' capital depends on the cost of the two capital sources and whether the capital gain is positive. To further fill the capital gap of SME suppliers, the optimal early payment period automatically triggered by FIMP is not the equilibrium solution of the traditional supply chain, but the point of maximizing the suppliers' profit when the buyer's benchmark profit is met. At this time, the DD efficiency can be greatly improved. To ensure rigor and robustness of the derived results, a sensitivity analysis of the parameters in the propositions was conducted, and the conclusions in the propositions were proved.

\subsection{Managerial implications and insights}

This study offers some managerial implications and insights for practitioners. First, in the traditional model, SMEs cannot access much information about the capital cost and supplier numbers; thus, it is difficult for them to raise working capital in a short invoice cycle. When increasing suppliers apply for DD, even if they can give an attractive discount rate to the buyer, the buyer may not have enough working capital to implement the DD program. Therefore, the emergence of the FIMP can effectively solve the problem of SME working capital shortages by creating a more equitable financing environment for more SMEs and provide a novel way for the supply and demand sides to gain profits.

Second, buyers can utilize FIMP-based DD to increase their margin. They can also release DD demand to their suppliers through the platform, encourage more suppliers to provide the DD program to their suppliers, and jointly improve the profit level of the supply chain. Further, more capital sources provided by the FIMP can solve the problem of working capital. However, it should be noted that when the discount rate provided is within a certain range, low working capital investment may cause the buyers' profit to be negative. Therefore, they should formulate a perfect capital utilization scheme for the DD program and optimize its own capital structure. 
Third, increasing the number of suppliers can solve the problem of capital shortages from the DD program based on the FIMP. In the FIMP, the suppliers can set and adjust the discount rate dynamically within a reasonable range (based on results in this study) to stimulate the buyers' acceptance of the discount application. Moreover, by adopting the FIMP, suppliers can quickly get the buyers' accurate payment period, rather than speculating whether and when the buyer will pay, which helps suppliers benefit from lower accounts receivable, eliminates capital uncertainty in the invoice cycle, and enables them to plan their production and operations in the next cycle.

\subsection{Future research direction}

This study focused on the DD program based on FIMP between homogeneous SME suppliers and one core enterprise buyer in a single invoice cycle. The research showed that the DD program supported by the FIMP can create profits for both suppliers and buyer. However, when the scale of suppliers, the number of invoices, the urgency of accounts receivable recovery is different and the dynamic discount rate change from linear to non-linear, it is worth exploring further how the key decision parameters change. Second, when there are multiple consecutive invoice periods, the buyers' capital cost may change seasonally and periodically. These factors will further affect the profits and decision-making results of both parties. In addition, the working capital constraints can sometimes affect the production and operation relationship of upstream and downstream enterprises in the supply chain. Future studies can explore whether the DD program based on FIMP has an impact on the production and operation decisions. Last, this study focuses on one of supply chain financial models the DD program. Apart from this model, accounts receivable financing, inventory financing, and other methods are also commonly applied as supply chain financial means. Studying the differences between them in alleviating the capital shortages of SMEs and exploring whether there is a possibility of paralleling these supply chain financial schemes simultaneously could be a potential research direction.

Acknowledgements This research has been supported, in part, by the National Natural Science Foundation of China (No. 71872177) and National Social Science Foundation of China (No. 21AZD015). The authors would like to thank two anonymous reviewers for their constructive comments which have led to improvements in this paper.

\section{References}

Babich, V., \& Kouvelis, P. (2018). Introduction to the special issue on research at the interface of finance, operations, and risk management (iform): Recent contributions and future directions. Manufacturing \& Service Operations Management, 20(1), 1-18. https://doi.org/10.1287/msom.2018.0706

Baldwin, C. Y., \& Woodard, C. J. (2009). The architecture of platforms: A unified view. Platforms, Markets and Innovation, 32, 19-44.

Bals, C. (2019). Toward a supply chain finance (scf) ecosystem - proposing a framework and agenda for future research. Journal of Purchasing and Supply Management, 25(2), 105-117.

Berger, A. N., \& Udell, G. F. (2006). A more complete conceptual framework for sme finance. Journal of Banking \& Finance, 30(11), 2945-2966. https://doi.org/10.1016/j.jbankfin.2006.05.008

Bi, G., Song, L., \& Fei, Y. (2018). Dynamic mixed-item inventory control with limited capital and short-term financing. Annals of Operations Research, 284(1), 99-130.

Bougheas, S., Mateut, S., \& Mizen, P. (2009). Corporate trade credit and inventories: New evidence of a trade-off from accounts payable and receivable. Journal of Banking \& Finance, 33(2), 300-307. https:// doi.org/10.1016/j.jbankfin.2008.07.019 
Boyson, S., Corsi, T., \& Verbraeck, A. (2003). The e-supply chain portal: a core business model. Transportation Research Part E: Logistics and Transportation Review, 39(2), 175-192. https://doi.org/10.1016/S13665545(02)00046-7

Caniato, F., Henke, M., \& Zsidisin, G. A. (2019). Supply chain finance: Historical foundations, current research, future developments. Journal of Purchasing and Supply Management, 25(2), 99-104. https://doi.org/10. 1016/j.pursup.2019.02.002

Chen, L., Chan, H. K., \& Zhao, X. (2020). Supply chain finance: Latest research topics and research opportunities. International Journal of Production Economics, 229, 541. https://doi.org/10.1016/j.ijpe.2020. 107766

Chen, Z., \& Rq, Zhang. (2021). A cash-constrained dynamic lot-sizing problem with loss of goodwill and credit-based loan. International Transactions in Operational Research, 28(5), 2841-2866. https://doi. org/10.1111/itor.12675

Chen, Z., Chen, J., Zhang, Z., \& Zhi, X. (2019). Does network governance based on banks' e-commerce platform facilitate supply chain financing? China Agricultural Economic Review, 11(4), 688-703. https:// doi.org/10.1108/CAER-06-2018-0132

Cheng, Y. M. (2020). Why do customers intend to continue using internet-based sharing economy service platforms? roles of network externality and service quality. Journal of Asia Business Studies, 15(1), $128-152$.

Coface (2020) China payment survey 2020: Payment delays will increase further because of covid19. https://www.coface.com/News-Publications/News/China-Payment-Survey-2020-Payment-delayswill-increase-further-because-of-COVID-19, accessed 30 September 2020

Connell (2014) Economic Impact of Late Payments. European Commission, directorate General Economic and Financial Affairs (DG ECFIN)

Demica (2007). Steady Supply: The Growing Role of Supply Chain Finance in a Changing World. London: Demica.

den Boer, A. V. (2015). Dynamic pricing and learning: Historical origins, current research, and new directions. Surveys in Operations Research and Management Science, 20(1), 1-18. https://doi.org/10.1016/j.sorms. 2015.03.001

Dou, G., Lin, X., \& Xu, X. (2018). Value-added service investment strategy of a two-sided platform with the negative intra-group network externality. Kybernetes, 47(5), 937-956. https://doi.org/10.1108/K06-2017-0215

Duan, C., Deng, C., Gharaei, A., Wu, J., \& Wang, B. (2018). Selective maintenance scheduling under stochastic maintenance quality with multiple maintenance actions. International Journal of Production Research, 56(23), 7160-7178. https://doi.org/10.1080/00207543.2018.1436789

Dubey, R., Gunasekaran, A., \& Sushil, Singh T. (2015). Building theory of sustainable manufacturing using total interpretive structural modelling. International Journal of Systems Science: Operations \& Logistics, 2(4), 231-247. https://doi.org/10.1080/23302674.2015.1025890

Farrell, D., \& Greig, F. (2016). Paychecks, paydays, and the online platform economy: Big data on income volatility. In: Annual Conference on Taxation and Minutes of the Annual Meeting of the National Tax Association, pp 1-40

Gelsomino, L. M., Mangiaracina, R., Perego, A., \& Tumino, A. (2016). Supply chain finance: a literature review. International Journal of Physical Distribution \& Logs Management, 46(4), 348-366. https://doi. org/10.1108/IJPDLM-08-2014-0173

Gelsomino, L. M., Mangiaracina, R., Perego, A., \& Tumino, A. (2016). Supply chain finance: Modelling a dynamic discounting programme. Journal of Advanced Management Science, 4(4), 283-291. https://doi. org/10.12720/joams.4.4.283-291

Gelsomino, L. M., Moretto, A., Caniato, F., \& Steeman, M. (2018). Innovative supply chain finance schemes: An exploratory study of dynamic discounting. Academy of Management Annual Meeting Proceedings, 1, 18089. https://doi.org/10.5465/AMBPP.2018.18089abstract

Gelsomino, L. M., de Boer, R., Steeman, M., \& Perego, A. (2019). An optimisation strategy for concurrent supply chain finance schemes. Journal of Purchasing and Supply Management, 25(2), 185-196. https:// doi.org/10.1016/j.pursup.2018.07.004, supply Chain Finance: Historical Foundations, Current Research, Future Developments

Gharaei, A., Karimi, M., \& Hoseini Shekarabi, S. A. (2019). An integrated multi-product, multi-buyer supply chain under penalty, green, and quality control polices and a vendor managed inventory with consignment stock agreement: The outer approximation with equality relaxation and augmented penalty algorithm. Applied Mathematical Modelling, 69, 223-254. https://doi.org/10.1016/j.apm.2018.11.035

Gharaei, A., Karimi, M., \& Shekarabi, S. A. H. (2020). Joint economic lot-sizing in multi-product multi-level integrated supply chains: Generalized benders decomposition. International Journal of Systems Science: Operations \& Logistics, 7(4), 309-325. https://doi.org/10.1080/23302674.2019.1585595 
Gharaei, A., Shekarabi, S. A. H., Karimi, M., Pourjavad, E., \& Amjadian, A. (2021). An integrated stochastic epq model under quality and green policies: Generalised cross decomposition under the separability approach. International Journal of Systems Science: Operations \& Logistics, 8(2), 119-131. https://doi. org/10.1080/23302674.2019.1656296

Giri, B. C., \& Bardhan, S. (2014). Coordinating a supply chain with backup supplier through buyback contract under supply disruption and uncertain demand. International journal of systems science: operations \& logistics, 1(4), 193-204.

Giri, B. C., \& Masanta, M. (2020). Developing a closed-loop supply chain model with price and quality dependent demand and learning in production in a stochastic environment. International Journal of Systems Science: Operations \& Logistics, 7(2), 147-163. https://doi.org/10.1080/23302674.2018.1542042

Group, T.H. (2018). Hackett: U.s. cos improve working capital performance; deterioration in receivables and inventory management masked by significant slowing of payments to suppliers. https://www. thehackettgroup.com/news/hackett-u-s-cos-improve-working-capital-performance-deterioration-inreceivables-and-inventory-management-masked-by-significant-slowing-ofpayments-to-suppliers/

Hermes, E. (2021). Covid19 to increase firms liquidity needs to a record usd8tn as payment delays and inventories surge. https://www.eulerhermes.com/en_global/newsinsights/economic-insights/Covid-19to-increase-firms-liquidity-needs-to-a-record-USD8tn-aspayment-delays-and-inventories-surge.html

Hofmann, E. (2009). Inventory financing in supply chains: A logistics service provider-approach. International Journal of Physical Distribution \& Logistics Management, 39(9), 716-740. https://doi.org/10.1108/ 09600030911008175

Hofmann, E., \& Kotzab, H. (2010). A supply chain-oriented approach of working capital management. Journal of Business Logistics, 31(2), 305-330. https://doi.org/10.1002/j.2158-1592.2010.tb00154.x

Hua, S., Yu, K., \& Qiang, L. (2018). Financial service providers and banks' role in helping smes to access finance. International Journal of Physical Distribution \& Logistics Management, 48(1), 69-92. https:// doi.org/10.1108/IJPDLM-11-2016-0315

Inc, T. (2005). Columbia sportswear company uses tradecard for more profitable procurement; automates financial transactions, collects early payment discounts. https://www.businesswire.com/news/home/ 20050503005862/en/Columbia-Sportswear-Company-TradeCard-Profitable-Procurement-Automates

Jaggi, C. K., Tiwari, S., \& Goel, S. K. (2017). Credit financing in economic ordering policies for noninstantaneous deteriorating items with price dependent demand and two storage facilities. Annals of Operations Research, 248(1-2), 253-280. https://doi.org/10.1007/s10479-016-2179-3

Jana, D. K., \& Das, B. (2017). A two-storage multi-item inventory model with hybrid number and nested price discount via hybrid heuristic algorithm. Annals of Operations Research, 248(1-2), 281-304. https://doi. org/10.1007/s10479-016-2162-z

Jia, F., Blome, C., Sun, H., Yang, Y., \& Zhi, B. (2020). Towards an integrated conceptual framework of supply chain finance: An information processing perspective. International Journal of Production Economics, 219, 18-30. https://doi.org/10.1016/j.ijpe.2019.05.013

Kazemi, N., Abdul-Rashid, S. H., Ghazilla, R., Shekarian, E., \& Zanoni, S. (2018). Economic order quantity models for items with imperfect quality and emission considerations. International Journal of Systems Science Operations \& Logistics, 5(2), 99-115.

Kopalle, P. K., Mela, C. F., \& Marsh, L. (1999). The dynamic effect of discounting on sales: Empirical analysis and normative pricing implications. Marketing Science, 18(3), 317-332. https://doi.org/10.1287/mksc. 18.3.317

Lahkani, M. J., Wang, S., Urbański, M., \& Egorova, M. (2020). Sustainable b2b e-commerce and blockchainbased supply chain finance. Sustainability, 12(3968), 3968. https://doi.org/10.3390/su12103968

Lamoureux, J. F., \& Evans, T. A. (2011). Supply chain finance: A new means to support the competitiveness and resilience of global value chains. SSRN Electronic Journal. https://doi.org/10.2139/ssrn.2179944

Lee, C. H., \& Rhee, B. D. (2011). Trade credit for supply chain coordination. European Journal of Operational Research, 214(1), 136-146. https://doi.org/10.1016/j.ejor.2011.04.004

Lekkakos, S. D., \& Serrano, A. (2016). Supply chain finance for small and medium sized enterprises: the case of reverse factoring. International Journal of Physical Distribution \& Logistics Management, 46(4), 367-392. https://doi.org/10.1108/IJPDLM-07-2014-0165

Ma, H. L., Wang, Z., \& Chan, F. T. (2020). How important are supply chain collaborative factors in supply chain finance? a view of financial service providers in china. International Journal of Production Economics, 219, 341-346. https://doi.org/10.1016/j.ijpe.2019.07.002

Matus, A., Guerra, E., Fuertes, W., Gómez, M., Aules, H., Villacís, C., \& Toulkeridis, T. (2017). On the development of an electronic invoicing solution to integrate smes with a tax-collection egovernmentplatform. In: 2017 Fourth International Conference on eDemocracy eGovernment (ICEDEG), pp 94-101, https://doi.org/10.1109/ICEDEG.2017.7962518 
More, D., \& Basu, P. (2013). Challenges of supply chain finance: A detailed study and a hierarchical model based on the experiences of an Indian firm. Business Process Management Journal, 19(4), 624-647. https://doi.org/10.1108/BPMJ-09-2012-0093

Narasimhan, C., Papatla, P., Jiang, B., Kopalle, P. K., Messinger, P. R., \& Sa, Moorthy. (2018). Sharing economy: Review of current research and future directions. Customer Needs and Solutions, 5(1-2), 93-106. https://doi.org/10.1007/s40547-017-0079-6

OECD. (2009). The impact of the global crisis on sme and entrepreneurship financing and policy responses. https://www.oecd.org/cfe/smes/theimpactoftheglobalcrisisonsmeandentrepreneurshipfinancingandpolicyresponses. htm

Oliveira, M., \& Handfield, R. (2017). An enactment theory model of supplier financial disruption risk mitigation. Supply Chain Management: An International Journal, 5, 442-457.

Pellegrino, R., Costantino, N., \& Tauro, D. (2019). Supply chain finance: A supply chain-oriented perspective to mitigate commodity risk and pricing volatility. Journal of Purchasing and Supply Management, 25(2), 118-133. https://doi.org/10.1016/j.pursup.2018.03.004, supply Chain Finance: Historical Foundations, Current Research, Future Developments

Pfohl, H. C., \& Gomm, M. (2009). Supply chain finance: Optimizing financial flows in supply chains. Logistics Research, 1(3-4), 149-161. https://doi.org/10.1007/s12159-009-0020-y

Rabbani, M., Hosseini-Mokhallesun, S. A. A., Ordibazar, A. H., \& Farrokhi-Asl, H. (2020). A hybrid robust possibilistic approach for a sustainable supply chain location-allocation network design. International Journal of Systems Science: Operations \& Logistics, 7(1), 60-75. https://doi.org/10.1080/23302674. 2018.1506061

Randall, W. S., \& Farris, M. T. (2009). Supply chain financing: Using cash-to-cash variables to strengthen the supply chain. International Journal of Physical Distribution \& Logistics Management, 39(8), 669-689. https://doi.org/10.1108/09600030910996314

Sarkar, S., \& Giri, B. C. (2020). Stochastic supply chain model with imperfect production and controllable defective rate. International Journal of Systems Science: Operations \& Logistics, 7(2), 133-146. https:// doi.org/10.1080/23302674.2018.1536231

Schor, J. B., \& Attwood-Charles, W. (2017). The sharing economy: Labor, inequality, and social connection on for-profit platforms. Sociology Compass, 11(8), 1751-9020. https://doi.org/10.1111/soc4.12493

Shah, N. H., Chaudhari, U., \& Cárdenas-Barrón, L. E. (2020). Integrating credit and replenishment policies for deteriorating items under quadratic demand in a three echelon supply chain. International Journal of Systems Science: Operations \& Logistics, 7(1), 34-45. https://doi.org/10.1080/23302674.2018.1487606

Shekarabi, S. A. H., Gharaei, A., \& Karimi, M. (2019). Modelling and optimal lot-sizing of integrated multilevel multi-wholesaler supply chains under the shortage and limited warehouse space: generalised outer approximation. International Journal of Systems Science: Operations \& Logistics, 6(3), 237-257. https:// doi.org/10.1080/23302674.2018.1435835

Shi, Y., Zhang, Z., Tiwari, S., \& Tao, Z. (2021). Retailer's optimal strategy for a perishable product with increasing demand under various payment schemes. Annals of Operations Research. https://doi.org/10. 1007/s10479-021-04074-4

Sokolinskiy, O., Melamed, B., \& Sopranzetti, B. (2018). Precautionary replenishment in financiallyconstrained inventory systems subject to credit rollover risk and supply disruption. Annals of Operations Research, 271(2), 971-997.

Song, H., Chen, S., \& Ganguly, A. (2019). Innovative ecosystem in enhancing hi-tech sme financing: Mediating role of two types of innovation capabilities. International Journal of Innovation Management, 24(2), 2050017. https://doi.org/10.1142/S1363919620500176

Spagnoletti, P., Resca, A., \& Lee, G. (2015). A design theory for digital platforms supporting online communities: A multiple case study. Journal of Information Technology, 30(4), 364-380. https://doi.org/10. 1057/jit.2014.37

Templar, S., Hofmann, E., \& Findlay, C. (2016). Financing the end-to-end supply chain: A reference guide to supply chain finance. London: Kogan Page Publishers.

Thangam, A. (2012). Optimal price discounting and lot-sizing policies for perishable items in a supply chain under advance payment scheme and two-echelon trade credits. International Journal of Production Economics, 139(2), 459-472. https://doi.org/10.1016/j.ijpe.2012.03.030 compassionate Operations.

Tiwana, A., Konsynski, B., \& Bush, A. A. (2010). Research commentary-platform evolution: Coevolution of platform architecture, governance, and environmental dynamics. Information Systems Research, 21(4), 675-687. https://doi.org/10.1287/isre.1100.0323

Wandfluh, M., Hofmann, E., \& Schoensleben, P. (2016). Financing buyer-supplier dyads: An empirical analysis on financial collaboration in the supply chain. International Journal of Logistics Research and Applications, 19(3), 200-217. https://doi.org/10.1080/13675567.2015.1065803 
Wandhöfer, R. (2019). Financing models for SMEs in the age of disintermediation. Cham: Springer International Publishing.

Wu, Y., \& Wang, Y. (2019). Collect payment early, late, or through a third party's reverse factoring in a supply chain. International Journal of Production Economics, 218, 245-259. https://doi.org/10.1016/j. ijpe.2019.04.040

Wuttke, D. A., Blome, C., Kai, F., \& Henke, M. (2013). Managing the innovation adoption of supply chain finance - empirical evidence from six european case studies. Journal of Business Logistics, 34(2), 148166. https://doi.org/10.1111/jbl.12016

Xiangjun, H., \& Lingyun, T. (2012). Exploration on building of visualization platform to innovate business operation pattern of supply chain finance. Physics Procedia. https://doi.org/10.1016/j.phpro.2012.05. 298

Yin, S., Nishi, T., \& Zhang, G. (2016). A game theoretic model for coordination of single manufacturer and multiple suppliers with quality variations under uncertain demands. International Journal of Systems Science: Operations \& Logistics, 3(2), 79-91. https://doi.org/10.1080/23302674.2015.1050079

Zhao, L., \& Huchzermeier, A. (2019). Managing supplier financial distress with advance payment discount and purchase order financing. Omega, 88, 77-90. https://doi.org/10.1016/j.omega.2018.10.019

Zhou, Z., Xiao, S., Ho, Y. C., \& Tan, Y. (2018). The persuasive and informative effects of information disclosure: Evidence from an online supply chain finance market. SSRN Electronic Journal. https://doi.org/10.2139/ ssrn. 3136240

Publisher's Note Springer Nature remains neutral with regard to jurisdictional claims in published maps and institutional affiliations. 